\title{
A Mycobacterium tuberculosis effector targets mitochondrion, controls energy metabolism and limits cytochrome c exit.
}

Marianne Martin', Angelique deVisch ${ }^{3}$, Philippe Barthe ${ }^{3}$, Obolbek Turapov², Talip Aydogan, Laurène Heriaud $^{3}$, Jerome Gracy ${ }^{3}$, Galina V. Mukamolova ${ }^{2}$, François Letourneur ${ }^{1 *}$, Martin CohenGonsaud $^{3 *}$

${ }^{1}$ Laboratory of Pathogen Host Interactions (LPHI), CNRS, University of Montpellier, France.

${ }^{2}$ Leicester Tuberculosis Research Group, Department of Respiratory Sciences, University of Leicester, UK.

${ }^{3}$ Centre de Biochimie Structurale, CNRS, INSERM, Université de Montpellier, France.

* Corresponding authors

\begin{abstract}
Host metabolism reprogramming is a key feature of Mycobacterium tuberculosis (Mtb) infection that enables the survival of this pathogen within phagocytic cells and modulates the immune response facilitating the spread of the tuberculosis disease. Here, we demonstrate that a previously uncharacterized secreted protein from $M t b, \mathrm{Rv1813c}$ manipulates the host metabolism by targeting mitochondria. When expressed in eukaryotic cells, the protein is delivered to the mitochondrial intermembrane space and enhances host ATP production by boosting the oxidative phosphorylation metabolic pathway. Furthermore, Rv1813c appears to differentially modulate the host cell response to oxidative stress. Expression of Rv1813 in host cells inhibits the release of cytochrome $\mathrm{c}$ from mitochondria, an early apoptotic event, in response to short-term oxidative stress. However, Rv1813c expressing cells showed increased sensitivity to prolonged stress. This study reveals a novel class of mitochondria targeting effectors from $M t b$ and opens new research directions on host metabolic reprogramming and apoptosis control.
\end{abstract}

\section{Introduction}

Mycobacterium tuberculosis (Mtb) encodes secreted virulence factors contributing to its successful infection of host cells and its ability to actively replicate inside the phagosome (Hmama et al., 2015) (Winden et al., 2019). After phagocytosis, Mtb blocks phagosomal maturation, escapes phagosomes and subverts the host immune response. Several virulence factors (e.g. proteins, lipids) have been already described to mediate such mechanisms, but corruption of host cell defense is clearly multifactorial (Nicholson et al., 2021). It is estimated that over $20 \%$ of bacterial proteins have functions outside the bacterial cytoplasm and are exported to their designated locations by protein 
export systems (Kostakioti et al., 2005). Identification of secreted proteins remains a challenging task. Data from various proteomic studies on secreted mycobacterial proteins have shown a weak overlap for proteins identified as secreted in different studies (Målen et al., 2007; Lange et al., 2014). As experiments were made in various culture conditions, it is not surprising that secretion patterns differ from one experiment to another. Furthermore, the host cell environment also plays an important role in defining the secretion pattern, as recently revealed by studies focusing on the identification of secreted proteins during infection (Perkowski et al., 2017; Penn et al., 2018). To get a broader view on the Mtb secretome, we used multidisciplinary approaches including bioinformatics, structural and biochemical techniques, and cellular biology analyses. We identified putative Mtb secreted proteins using proteins primary sequence analysis combined with structure modelling. Among the selected targets, we studied the protein coded by the $r v 1813 c$ gene which is only present in mycobacterial pathogens. The Rv1813c protein has been used as vaccine adjuvant (Bertholet et al., 2008) and displays immunogenicity properties (Liang et al., 2019). Rv1813c expression was reported to be MprA and DosR regulated (Bretl et al., 2012) and Mtb $\Delta$ Rv1813c mutant was attenuated in the low-dose aerosol model of murine tuberculosis (Bretl et al., 2012). In this paper we describe extensive molecular and functional analyses of this protein. We showed that Rv1813c defines a new class of effectors, with an original fold, addressed to mitochondria. Mitochondrion plays critical functions not only supplying cells with energy but also contributing to several cellular mechanisms including cell cycle, apoptosis, and signaling pathways. Metabolism modulation dictates macrophage function and subsequent Mtb infection progression. Here, we demonstrate for the first time that Rv1813c affects the mitochondrial metabolic functions and the cell response to oxidative stress. Together these results suggest that Rv1813c might be a key regulator of the metabolic shift and apoptosis regulation occurring in Mtb infected macrophages

\section{Results}

\section{Bioinformatic analysis of $M t b$ genome for identification of secreted proteins}

Mtb possesses at least three different secretion systems (Feltcher et al., 2010). The general secretion (Sec) and the twin-arginine translocation (Tat) pathways perform the bulk of protein export and are both essential for growth. Proteins exported by the Sec pathway are distinguished by the presence of an $\mathrm{N}$-terminal signal recognized by the SecA proteins before translocation. The Tat pathway exports preproteins containing $\mathrm{N}$-terminal signal peptides with a twin-arginine motif for binding to the TatC protein. Mtb has also specialized export pathways that transport subsets of proteins. Five specialized ESX export systems (ESX-1 to ESX-5) are present in Mtb with some of them essential for virulence (Brodin et al., 2006)(Tran et al. 2021). The ESX systems are also referred to as Type VII secretion systems (T7SS). Proteins secreted by T7SS lack Sec or Tat signal peptides, instead secretion relies on a combination of a sequence and a structural motif (Daleke et al., 2012). We analyzed the predicted Mtb H37Rv proteome using an in-house Protein Analysis Toolkit (PAT) 2/1/21 
11:50:00 AM. First, known signal peptides and/or structural features necessary for secretion were predicted using SignalP v4.1 and PredTAT softwares. In addition, transmembrane segments were inferred using either Uniprot annotations or the TmHMM prediction software. The number of predicted transmembrane segments and the position of the last transmembrane segment were also analyzed to identify signals potentially missed by the other servers. To search for potential T7SSmediated secreted proteins, we first performed helix structure prediction within the first 80 residues of each protein using Psipred (McGuffin et al., 2000), and then searched for the YxxxD/E motif in between the two helices. These data were compared with various proteomic data and model databases (ModBase, Interpro, GO). Using this approach, we identified 118 putative T7SS-, 124 putative Tat-, and 350 putative Sec-mediated secreted Mtb proteins. Proteins to be studied further were selected if they met one of the following criteria linked to a putative host-pathogen interaction: i) a small domain of unknown function, ii) a protein/protein interaction domain, iii) a "eukaryotic" domain (e.g., arrestin). Among the proteins identified as potentially secreted, we studied Rv1813c, a 143 amino-acid protein, not previously identified as secreted and comprising a predicted folded domain of unknown function.

\section{Rv1813c protein sequence features}

Primary sequence analysis of the Rv1813c protein unambiguously identified a potential signal sequence (residues 1 to 28 ) with an upstream arginine repeat (residues 6-8) indicating that the protein could be exported by the TAT export system (Fig. 1A). Homologous proteins are mostly found in Actinobacteria (Mycobacterium, Nocardia and Streptomyces genera). In addition to Mtb, the protein is present in various mycobacteria including Mycobacterium marinum (Mmar), Mycobacterium avium, Mycobacterium ulcerans and Mycobacterium abscessus. Multiple paralogues exist within the same bacteria. For instance, Mtb possesses only one orthologue (Rv1269c) whereas Mmar harbors three paralogues (MMAR_1426, MMAR_2533 and MMAR_4153). The sequence homology between these various proteins is high (between 45 to $70 \%$ ), with a lower sequence identity for the $\mathrm{N}$-terminal part of the protein (Fig. 1A). Four cysteine residues are present and conserved. The last four amino acid residues $\left({ }^{140} \mathrm{WACN}^{143}\right)$ composed a strictly conserved motif that includes one of the conserved cysteines. Fold-recognition and modelling server @TOME2 previously used in many studies for protein function identification even at low sequence identity (Turapov et al., 2014) did not identify any close or distant Rv1813c structural homologues.

\section{Rv1813c is secreted by M. tuberculosis in broth culture}

Despite its use as vaccine adjuvant (Bertholet et al., 2008), its immunogenicity properties (Liang et al., 2019) and a clear secretion signal sequence, no published proteomic to date have identified Rv1813c as a secreted protein, possibly due to the small size of the protein. Western blot analyses were carried out using a rabbit polyclonal antibody developed against recombinant Rv1813c (see 
below). As shown in Fig. 2, Rv1813c was detected in the Mtb culture filtrate but not in any of the cellular fractions including the cell wall. This result suggests that Rv1813c is secreted during active growth in culture medium and is not bound to the bacteria cell wall.

\section{Rv1813c defines a new protein family and a unique fold}

The Rv1813c-coding sequence without the first codons corresponding to the protein signal peptide (residues 1 to 27) was cloned into an Escherichia coli expression vector. The protein was overexpressed as inclusion bodies, purified and refolded. Circular dichroism experiments demonstrated that the recombinant protein was folded, and SEC-MALS analysis (Size Exclusion Chromatography - Multi Angle Light Scattering) confirmed that the sample size matched the predicted folded monomer size. Next, the purified protein was used for multidimensional NMR experiments. Preliminary examination of $[1 \mathrm{H}, 15 \mathrm{~N}]-\mathrm{HSQC}$ spectrum revealed that 30 residues were unfolded (Supplementary Fig. S1). A full multi-dimensional NMR study led to the protein three-dimensional structure resolution (Fig. 1B, Supplementary Table S1). Structure resolution demonstrated that the residues 28 to 57 were unfolded and that the protein possessed a 86 residues folded domain. This domain is composed of two duplicate lobes facing each other, certainly inherited from a duplication despite a lack of sequence homology. Each lobe is a series of three $\beta$-strands with an hydrophobic surfaces and an $a$-helix $(B / \beta / \alpha / \beta)$. The four conserved cysteines are engaged in disulphide bonds but, noteworthy, the two di-sulfide bonds are located in different parts of each lobe. The conserved WACN motif cysteine is engaged in a disulfide bond linking the strands $B 6$ and $B 4$, while its tryptophan is solvent exposed (as is also the second protein tryptophan). We hypothetically assumed that this solvent exposed tryptophan might be important for the protein function (i.e. hydrophobic binding or protein surface recognition). The overall structure defines a previously undescribed fold as both Dali (Holm and Rosenström, 2010) and FATCAT (Ye and Godzik, 2004) servers failed to detect any structural homologues. Consequently, sequence and structure comparison analysis did not bring any indication on the potential biological function of the Rv1813c protein family.

\section{Rv1813c is addressed to mitochondria in Dictyostelium discoideum.}

To assess the function of Rv1813c in host cells, we first used the amoeba Dictyostelium discoideum. This professional phagocyte is amenable to biochemical, cell biological and genetic approaches, and has proved to be an advantageous host cell model to analyze the virulence of several pathogenic bacteria (Steinert, 2011; Müller-Taubenberger et al., 2013). Furthermore, the intracellular replication of Mmar has been extensively studied in $D$. discoideum and shows similarity to Mtb replication (Cardenal-Muñoz et al., 2017), indicating that comparable molecular mechanisms are at play in infected $D$. discoideum and mammalian host cells. We first analyzed the intracellular localisation of Rv1813c when overexpressed in D. discoideum (ectopic expression). Though protein ex- 
pression levels might differ from what is encountered during Mtb infection, ectopic expression allows the advantageous analysis of individual secreted mycobacterial proteins without the interference of other bacterial effectors. Rv1813c deleted of its predicted signal peptide (first 27 amino acid residues) was tagged with a myc epitope at its N-terminus (myc-Rv1813c_P28-N143, here after referred to as myc-Rv1813c) and stably expressed in D. discoideum. Confocal microscopy analysis revealed colocalization in ring like structures of myc-Rv1813c coinciding with a mitochondrial outer membrane protein, Mitoporin (Troll et al., 1992) (Fig. 3A). Mitochondrial targeting was also observed in cells expressing Rv1813c tagged at the C-terminus (Rv1813c-myc) but was lost when Rv1813c was fused to GFP (data not shown). This specific targeting was independent of the added myc-tag as staining with an anti-Rv1813c polyclonal antibody of untagged $R v 1813 \mathrm{c}$ showed identical results (Supplementary Fig. S2A). Mitoporin staining patterns were similarly observed in both recipient (Ax2) and Rv1813c transfected cells (Supplementary Fig. S2A, S2B) excluding gross mitochondrial morphological defects induced by Rv1813c expression in $D$. discoideum. In cells labeled with mitotracker deep red, a specific dye accumulating inside mitochondria, myc-Rv1813c surrounded labeled mitochondria and was mostly excluded from internal structures (Fig. 3B). This result suggested that Rv1813c might be attached either to the internal or the cytosolic sides of mitochondrial outer membranes. Interestingly, deletion of the unfolded $\mathrm{N}$-terminus region of Rv1813c (myc-Rv1813c_49-143) had no effect on Rv1813c localization whereas Rv1813c deprived of the folded region (myc-Rv1813c_28-56) was not transported to mitochondria (Fig. 3C). Thus, the Rv1813c folded domain, which does not contain any known mitochondrial targeting signals, was sufficient to specifically direct this protein to mitochondrial outer membranes.

\section{Rv1813c homologues are addressed to mitochondria in $D$. discoideum}

Intracellular localization was next extended to members of the Rv1813c family in Mtb and Mmar. All these proteins were detected in mitochondria, however some Rv1813c-like proteins affected mitochondria morphology. Whereas overexpression of Rv1813c Mmar orthologs (MMA_1426 and MMA_2533) did not induce any apparent morphological defects in mitochondria, cells expressing Rv1269c or its Mmar ortholog MMA_4153 displayed mitochondria with aberrant shapes and sizes (Supplementary Fig. S2C). In addition to mitochondria, MMA_4153 also localized to the cytosol. Together these results indicated that mitochondrial targeting is a characteristic feature of the Rv1813c family, and for some members, this localization leads to defective mitochondrial morphology.

\section{Rv1813c resides in the mitochondrial inter membrane space}

Mitochondria are composed of two membranes, the outer and inner membranes, separated by an inter membrane space (IMS). To determine more precisely the localization of Rv1813c within these 
submitochondrial compartments, we next applied a biochemical approach. First, mitochondria enriched fractions (here after referred to as mitochondria) were obtained by subcellular fractionation (see scheme Fig. 4A). As expected, Rv1813c was recovered from the mitochondrial fraction confirmed by Mitoporin enrichment (Fig. 4B). Next, Triton X-114 phase partitioning experiments revealed that Rv1813c is not an integral membrane protein, in agreement with the absence of any predicted transmembrane domains (Fig. 4C) and its exclusion from the Mtb cell wall (Fig. 2). Consistently, Rv1813c was extracted from mitochondrial membranes by sodium carbonate treatment, a characteristic feature of peripheral membrane proteins (Fig. 4D). Since Rv1813c was not released from mitochondria by high salt washes (Fig. 4E) and was protected from proteinase $\mathrm{K}$ digestion of intact mitochondria (Fig. 4F), we concluded that Rv1813c resides inside mitochondria. In addition, Rv1813c was partially released from mitochondria upon the specific rupture of mitochondrial outer membranes in hypotonic medium indicating that Rv1813c accumulates into the mitochondrial IMS (Fig. 4G).

\section{Rv1813c disturbs mitochondrial membrane potential but not ROS production}

To assess whether Rv1813c mitochondrial localization might interfere with mitochondrial functions, we monitored the mitochondrial membrane potential $\left(\Delta \Psi_{\mathrm{M}}\right)$, a key indicator of mitochondrial activity. We used the membrane-permeant $\mathrm{JC}-1$ dye which accumulates in healthy mitochondria and forms aggregates exhibiting a fluorescence emission shift from green ( $\sim 29 \mathrm{~nm})$ to red ( 590 nm) which can be easily followed by flow cytometry. Here we noticed that Rv1813c expressing cells showed an increased JC1-1 red/green ratio, consistent with an elevated mitochondrial membrane potential compared to recipient cells (Fig. 4H). Interestingly, this high $\Delta \Psi_{\mathrm{M}}$ was not associated with an increased production of mitochondrial reactive oxygen species (ROS) as assayed by flow cytometry analysis of MitoSox stained cells (Fig. 4I).

\section{Rv1813c overexpression increases cell death upon oxidative stress in $D$. discoideum}

In addition to energetic and metabolism regulatory functions, mitochondria play essential roles in cell death induced in response to oxidative stress. To test whether Rv1813c might impede this mitochondrial function, cells were treated with hydrogen peroxide and observed by phase contrast microscopy. Samples with cells overexpressing Rv1813c showed increased number of shrank and broken cells upon addition of $0.4 \mathrm{mM}$ hydrogen peroxide for four hours compared to recipient cells (Fig. 4J). Quantification of cell viability by propidium iodide (PI) incubation and flow cytometry analysis revealed that Rv1813c overexpression significantly increased oxidative stress sensitivity of Dictyostelium (Fig. 4K). Together these data indicated that Rv1813c targeting to mitochondria results in deleterious mitochondrial functions in resting cells further amplified under stress conditions. 


\section{Rv1813c protein family members are addressed to mitochondria in mammalian cells}

We next extended the analysis to mammalian host cells. Native and myc-Rv1813c were transiently expressed in HeLa cells and their intracellular localization was determined by confocal microscopy. As observed in Dictyostelium, Rv1813c was efficiently targeted to mitochondria (Fig. 5A and Supplementary Fig. S3) without any detectable morphological effects (Fig. 5B). MMA_1436 and MMA_2533, two Mmar orthologs of Rv1813c also localized to mitochondria in HeLa cells. In contrast, Rv1269c remained in the cytosol both in HeLa and HEK293 cells (Supplementary Fig. S3 and Fig. S4). For MMA_4153, the Mmar orthologs of Rv1269c, a faint mitochondrial staining was detected in both cell types. Though mitochondrial targeting might be dependent upon the expression level of ectopic proteins (expression in HEK293 cells gives a better yield), Rv1269c and MMA_4153 might be incorrectly/partially folded when expressed in mammalian cells, as observed in heterologous expression in E. coli, preventing efficient mitochondrial localization.

Whereas the overall morphology of mitochondria was preserved upon Rv1813c ectopic expression, transmission electronic microscopy (TEM) revealed some ultrastructural modifications. Hence, Rv1813c expressing cells contained mitochondria with either normal or electron-dense matrix, and the intra-cristae space appeared significantly enlarged compared to native HeLa cells, a modification observed by in Mtb H37Rv-infected macrophages (Abarca-Rojano et al., 2003) (Fig. 5D, 5E and 5F). More important defects were also observed upon expression of Rv1813c in HEK 293 cells providing higher protein expression levels than in HeLa cells (Supplementary Fig. S5). Since cristae membranes are enriched in proteins involved in oxidative phosphorylation, this particular ultrastructure might lead to mitochondrial energetic/metabolism consequences.

\section{Rv1813c overexpression enhances cell metabolism and mitochondrial ROS production}

The observed changes in mitochondrial ultrastructure triggered by Rv1813c prompted us to test whether they were associated with energy metabolism disorders. Oxidative phosphorylation (OXPHOS) and glycolysis were simultaneously analyzed in intact cells making use of an extracellular flux analyzer (XF, Agilent Seahorse). In this assay, mitochondrial respiratory characteristics are evaluated by recording oxygen consumption rate $(\mathrm{OCR})$ upon sequential chemical perturbation of selected mitochondrial functions (as detailed in figure 6 legend). In Rv1813c transfected cells, basal respiration, ATP-linked respiration, maximal respiratory capacity and reserve capacity were significantly increased compared to native HeLa cells (Fig. 6A). Glycolysis was also assayed using a glycolysis stress test (Agilent Technologies) and measurements of extracellular acidification rates (ECAR) in incubation media. This assay revealed similar glycolytic profiles in control and Rv1813c expressing HeLa cells (Fig. 6B). Next, mitochondrial membrane potential was tested using flow cytometry of JC-1 stained cells. In contrast to Dictyostelium, expression of Rv1813c in Hela cells had no effect on $\Delta \Psi_{M}$ in resting cells (Fig. 6C). However, these cells showed a slight but significant increased mitochondrial ROS production (Fig. 6D). Together results of these assays indicated that 
Rv1813c expression improves mitochondrial respiratory capacities without altering glycolytic functions, driving cells into an energy activated state. This higher mitochondrial respiration was associated with increased mitochondrial free radical formation without changes in the mitochondrial membrane potential.

\section{Rv1813c promotes cell death in response to prolonged oxidative stress}

We next assessed whether these mitochondrial alterations might alter the ability of Rv1813c expressing mammalian cells to cope with oxidative stress, a feature of $M t b$ infection. Cells were incubated in medium supplemented with increasing amounts of hydrogen peroxide (0.075 to 0.3 $\mathrm{mM}$ ). After $8 \mathrm{~h}$ and $24 \mathrm{~h}$, cell death was monitored by $\mathrm{PI}$ and Annexin $\mathrm{V}$ staining followed by flow cytometry analysis. A first set of experiments using Hela cells resulted only in minor effects of Rv1813c (data not shown). However, making use of HEK293 as recipient cells revealed an important increase of total Annexin $\mathrm{V}$ positive cells (early and late apoptosis) in response to $0.15 \mathrm{mM}$ hydrogen peroxide over time in Rv1813c overexpressing cells compared to recipient cells (Fig. 6E). This increase was maximal after $24 \mathrm{~h}$ at $0.15 \mathrm{mM}$ hydrogen peroxide whereas doubling this concentration resulted in similar massive cell death even in empty vector transfected recipient cells (Fig. 6F). Thus, as observed in $D$. discoideum, Rv1813c expression in mammalian cells enhanced the sensitivity of cells to oxidative stress.

\section{Short-term oxidative stress induces Rv1813c translocation and delays in cytochrome c re- lease from mitochondria}

Cytochrome c (Cyt-c) release from mitochondria into the cytosol is an early event in apoptotic cell death in response to hydrogen peroxide (Stridh et al., 1998). To monitor this event, cells were incubated with hydrogen peroxide for only three hours. Cyt-c and Rv1813c localizations were then analyzed by confocal microscopy and quantified. As expected, Cyt-c showed a diffuse cytosolic staining in $21 \%$ of HeLa cells upon addition of $0.1 \mathrm{mM}$ hydrogen peroxide (Fig. 7A,B). Rv1813c release from mitochondria was also observed in cells overexpressing Rv1813c in response to hydrogen peroxide treatments (Fig. 7C). In contrast, Cyt-c release from mitochondria into the cytosol was reduced in Rv1813c expressing cells, with only $7.9 \%$ of cells displaying a cytosolic Cyt-c staining upon oxidative stress conditions (Fig. 7A,B). Note that cells with cytosolic Cyt-c always showed concomitant Rv1813c cytosolic localization. Strikingly, Rv1813c release from mitochondria was more frequently observed than Cyt-c translocation leading to another cell population with Rv1813c in the cytosol but Cyt-c still in mitochondria (Fig. 7D). Rv1813c mitochondrial exit in response to oxidative stress might be necessary for Cyt-c exit. As a whole, these results strongly suggested that Rv1813c inhibits efficient Cyt-c translocation and possibly early apoptotic associated events. 


\section{Discussion}

Intracellular pathogens (i.e. Rickettsia, Legionella, Salmonella) disrupt mitochondrial function mainly due to indirect effects (Spier et al., 2019)(Garaude, 2019). Few effectors are directly targeting the organelle (Hicks and Galán, 2013). For instance, EspF effector from enteropathogenic E. coli induces cell death (Hua et al., 2018). After injection to the intestinal epithelial cells, EspF effector is targeted to the mitochondria via a mitochondrial import signal and promotes caspase mediated apoptosis (Hua et al., 2018). Recently it was demonstrated that the MitF protein from L. pneumophilia alters mitochondria fission dynamics and a consequence promotes a Warburg-like phenotype in macrophages (Escoll et al., 2017). Using bioinformatics screening and functional analysis, we have identified Rv1813c from Mtb as a putative secreted protein and established that Rv1813c belongs to a new protein family specifically addressed to mitochondria. Furthermore, we demonstrated that ectopic expression of Rv1813c in D. discoideum induced strong functional defects in eukaryotic cells. In Mycobrowser (https://mycobrowser.epfl.ch) and other Mtb databases, Rv1813c is currently annotated as a "conserved hypothetical protein". Despite being used as a vaccine adjuvant (Bertholet et al., 2008) and its high immunogenicity (Liang et al., 2019), no functional information is available to our knowledge. The gene is non-essential for growth, however its deletion impaired virulence in low dose murine model (Bretl et al., 2012). Yet the precise mechanism of this attenuation is currently unknown.

The structure of Rv1813c solved here defines a new protein folding with no homology with any structures solved to date (Fig 1). The small $9 \mathrm{kDa}$ folded domain, which includes a highly conserved C-terminal motif $\left({ }^{140} \mathrm{WACN}^{143}\right)$, is sufficient to specifically address the protein into mitochondria where it accumulates the IMS (Fig. 3 and Fig. 4). Noteworthy the efficiency of this mitochondrial targeting differs among the family members analyzed. The highly divergent primary sequences of the $\mathrm{N}$-terminal unfolded parts might be responsible for this difference, possibly by impacting the whole protein dynamics and stability.

The only previously published study on Rv1813c reported that MprA and DosR regulate its expression (Bretl et al., 2012). DosR is a transcriptional regulator induced by host intracellular stimuli, such as nitric oxide (NO), carbon monoxide (CO), and hypoxia (Bretl et al., 2012), while MrpA responses to environmental stress and within the macrophage (Haydel and Clark-Curtiss, 2004;(Pan et al., 2020) and is required during infection (Zahrt and Deretic, 2001). Reference transcriptomic studies have revealed that Rv1813c is over-expressed ( $x 2$ and $x 4,24 \mathrm{~h}$ and $48 \mathrm{~h}$ post-infection, respectively) in activated infected macrophages (Schnappinger et al., 2006), and in BLAC mouse model (x5, x14 then $x 2,7$ days 14 days and 28 days post-infection, respectively) (Talaat et al., 2004). Here we confirmed that the protein is constitutively secreted by Mtb in culture medium and its overexpression in host cells results in phenotypes linked to its localisation into the mitochondrial IMS. Hence, we demonstrate that ectopically expressed Rv1813c i) enhances OXPHOS, ii) increases cell death under prolonged oxidative stress, iii) inhibits cytochrome-c exit upon short-term oxidative stress. 
While more in vivo experiments will be necessary to fully understand the function of Rv1813c, the three main Rv1813c-dependent defects revealed in our study are clearly connected to important host defence mechanisms against Mtb infections.

Does the secretion of this Mtb effector protein increase mitochondrial ATP production in host cells bring any substantial intracellular replication advantages or help to prevent host cell defenses? Efficient response to $M t b$ infection by macrophages relies on their activation leading to polarisation toward an M1 profile (Shi et al., 2019). This is achieved by a metabolic reprogramming after Nf-kB activation either by pathogen-associated molecular patterns (PAMPs) or IFN $\gamma$. Nf-kB promotes the expression of the inducible nitric oxide synthase (iNOS) and subsequent nitric oxide (NO) release. Besides bactericidal activity, NO directly inactivates the electron transfer chain (ETC) proteins, triggering a complex series of events, mainly dependent to reactive oxygen species (ROS) production and metabolites balance changes (i.e. NAD/NADP ratio). When the Krebs cycle is consequently blocked, citrate accumulates enhancing glycolysis and lipids biosynthesis. In addition, succinate also accumulates leading to HIF-1 $\alpha$ (Hypoxia-inducible factor-1) stabilisation, which results in a complete metabolic switch similar to the Warburg effect in tumours (Shi et al., 2016). HIF-1 $\alpha$ not only promotes the expression of enzymes involved in glycolytic ATP production, but also induces expression pattern leading to synthesis of important immune effectors, including inflammatory cytokines and chemokines under normoxic conditions. Therefore, full M1 polarisation is essential for defense to pathogenic infections, and appears as a target choice for Mtb (Wilson et al., 2019).

Very few studies have assessed the precise metabolic state of Mtb infected cells (Mohareer et al., 2020). Recently, bioenergetic analyses have been performed on infected macrophages. XF experiments and metabolites analysis using ${ }^{13} \mathrm{C}$-tracing in infected macrophages have revealed a decreased of cell energetic flux through glycolysis and the TCA cycle. Consequently, the total level of ATP produced in Mtb infected cells 5 and 24 hours post infection is decreased (Cumming et al., 2018). However, different effects are observed with BCG or dead Mtb, which do not gain access to the cytosol or release effector proteins in the cytosol after phagocytosis (Simeone et al., 2012). Hence, the glycolytic flux is enhanced with these two strains in contrast to virulent H37rv bacteria. These results suggest a weaker metabolic macrophage response to virulent $M t b$ infection that might be controlled by bacterial effectors leading to incomplete or delayed metabolic shift.

On the other hand, studies have proposed that maintaining the ATP production is beneficial for $M t b$, avoiding ROS production and apoptosis. For instance, a much higher ATP/ADP ration was observed in H37Rv-infected cells compared to cells infected with avirulent H37Ra, a strain that does not escape from phagosomes to access the cytosol (Jamwal et al., 2013)(Jamwal et al., 2016). An elevated ATP/ADP ratio was further correlated to lower apoptosis rates observed in H37Rvinfected cells (Jamwal et al., 2013)(Mehrotra et al., 2014). Together these data indicate that maintaining a high ATP production might be beneficial to delay a deleterious full metabolic shift and/or apoptosis of the host-cell. Comforting this hypothesis, secretion of Rv1813c could participate in 
maintaining a higher ATP production within mitochondria during Mtb infection. Moreover, a recent study indicates that the anti-mycobacterial drug Bedaquiline disturbs the host metabolism and increases the macrophage resistance to various bacterial infection without direct inhibition of the pathogens (Giraud-Gatineau et al., 2020). While some diverging results have been reported (Belosludtsev et al., 2019) (Luo et al., 2020), it is well-established that host ATP production is reduced in Bedaquiline-treated eukaryotic cells and this may contribute to successful Mtb elimination.

Our results also indicate that Rv1813c displays both anti-apoptotic and pro-apoptotic effects upon short-term and prolonged oxidative stress respectively. Mitochondrial proton leak generated from the ETC is the major source of mitochondrial ROS. ROS excess results in multiple effects including cytochrome-c translocation followed by caspase dependent apoptosis as well as inflammasome activation (Jamwal et al., 2013). Our bioenergetics and microscopy experimental data indicate that Rv1813c expression does not modify mitochondria numbers. Instead ETC and/or ATP synthase boosted functions are likely to account for the observed ATP increased production. Accordingly, Rv1813c ectopic expression induces a slight increase of ROS in resting cells (Fig. 6D). Among multiple cellular effects, hydrogen peroxide dramatically increases ROS production, eventually leading to cell death by apoptosis and/or necrosis. Due to higher basal ETC activity, Rv1813c expressing cells might already cope for elevated ROS levels, and might be more sensitive to any further elevated ROS levels, induced for instance by hydrogen peroxide treatments. This would result in the reduction of the ROS level below the threshold that normally triggers cell death. This hypothesis might thus explain the increase sensitivity of Dictyostelium and mammalian cells to prolonged oxidative stress. Surprisingly, Rv1813c expression produces opposite effects upon shortterm oxidative stress, inhibiting the release of Cyt-c from mitochondria, which is fully consistent with an anti-apoptotic function. Several mechanisms have been described to explain the exit of Cyt-c from mitochondria during apoptosis (Garrido et al., 2006). Our data indicate that mitochondrial membrane rupture does not participate in the release of Cyt-c since mitochondria keep their integrity to selectively retain Cyt-c but release Rv1813c (Fig. 7). Though we cannot exclude that Rv1813c might inhibit a cardiolipins dependent mechanism (Barayeu et al., 2019), our working hypothesis is that Rv1813c might interfere with the BAX/BAK pore formation in mitochondrial outer membranes required for Cyt-c exit.

Overall, our results on Rv1813c pave the way to further characterisation on the establishment of metabolic shift and apoptosis regulation occurring in Mtb infected macrophages 
Detailed methods are provided in Supplementary Materials and Methods of this paper and include the following:

- Purification of recombinant ${ }^{6} \mathrm{His}-\mathrm{Rv} 1813 \mathrm{c}_{28-143}$ in E. coli

- Solution structure of Rv1813c $28-143$

- Antibodies

- Preparation of Mycobacterium tuberculosis culture

- Mycobacterial cell fractionation

- Protein Electrophoresis and Western Blot

- Cell culture and transfection conditions

- Mitochondria isolation and biochemical treatments

- Immunocytochemistry

- Flow cytometry analysis of JC-1, MitoSox and Annexin 5/PI stained cells

- MACS enrichment of CD4-Rv1813c transfected cells

- Extracellular flux analysis

- Transmission electron microscopy

\section{AUTHOR CONTRIBUTION}

MM, AdV, PB, YMB, OP, TA, LH, JG, CG, GM, FL and MCG performed experiments; MM, GM, CG, $\mathrm{ON}, \mathrm{FL}$ and MCG analysed the data; FL and MCG conceived this study; All authors contributed to manuscript writing.

\section{AKNOWLEDGEMENTS}

Flow cytometry and microscopy analyses of uninfected cells were performed at the Montpellier RIO imaging facility of the University of Montpellier, member of the national infrastructure FranceBiolmaging, supported by the French National Research Agency (ANR-10-INBS-04, "Investments for the future"). The CBS acknowledges support from the French Infrastructure for Integrated Structural Biology (FRISBI) ANR-10-INSB-05-01. The following reagents were obtained through BEI Resources, NIAID, NIH: Monoclonal Anti-M. tuberculosis GInA (Gene Rv2220), Clone IT-58 (CBA5) (produced in vitro), NR-44103; Polyclonal Anti-Mycobacterium tuberculosis FtsZ (Gene Rv2150c) (antiserum rabbit).

\section{DECLATION OF INTERESTS}

The authors declare no competing interests. 


\section{References}

Abarca-Rojano, E., Rosas-Medina, P., Zamudio-Cortéz, P., Mondragón-Flores, R., and SánchezGarcía, F.J. (2003). Mycobacterium tuberculosis virulence correlates with mitochondrial cytochrome c release in infected macrophages. Scand J Immunol 58, 419-427.

Barayeu, U., Lange, M., Méndez, L., Arnhold, J., Shadyro, O.I., Fedorova, M., and Flemmig, J. (2019). Cytochrome c autocatalyzed carbonylation in the presence of hydrogen peroxide and cardiolipins. J Biol Chem 294, 1816-1830.

Belosludtsev, K.N., Belosludtseva, N.V., Talanov, E.Y., Tenkov, K.S., Starinets, V.S., Agafonov, A.V., Pavlik, L.L., and Dubinin, M.V. (2019). Effect of bedaquiline on the functions of rat liver mitochondria. Biochimica et Biophysica Acta (BBA) - Biomembranes 1861, 288-297.

Bertholet, S., Ireton, G.C., Kahn, M., Guderian, J., Mohamath, R., Stride, N., Laughlin, E.M., Baldwin, S.L., Vedvick, T.S., Coler, R.N., et al. (2008). Identification of Human T Cell Antigens for the Development of Vaccines Against Mycobacterium Tuberculosis. J Immunol 181, 7948-7957.

Bretl, D.J., He, H., Demetriadou, C., White, M.J., Penoske, R.M., Salzman, N.H., and Zahrt, T.C. (2012). MprA and DosR coregulate a Mycobacterium tuberculosis virulence operon encoding Rv1813c and Rv1812c. Infect. Immun. 80, 3018-3033.

Brodin, P., Majlessi, L., Marsollier, L., de Jonge, M.I., Bottai, D., Demangel, C., Hinds, J., Neyrolles, O., Butcher, P.D., Leclerc, C., et al. (2006). Dissection of ESAT-6 system 1 of Mycobacterium tuberculosis and impact on immunogenicity and virulence. Infect Immun 74, 88-98.

Cardenal-Muñoz, E., Barisch, C., Lefrançois, L.H., López-Jiménez, A.T., and Soldati, T. (2017). When Dicty Met Myco, a (Not So) Romantic Story about One Amoeba and Its Intracellular Pathogen. Front Cell Infect Microbiol 7, 529.

Cumming, B.M., Addicott, K.W., Adamson, J.H., and Steyn, A.J. (2018). Mycobacterium tuberculosis induces decelerated bioenergetic metabolism in human macrophages. Elife 7.

Daleke, M.H., Ummels, R., Bawono, P., Heringa, J., Vandenbroucke-Grauls, C.M.J.E., Luirink, J., and Bitter, W. (2012). General secretion signal for the mycobacterial type VII secretion pathway. Proc Natl Acad Sci U S A 109, 11342-11347.

Escoll, P., Song, O.-R., Viana, F., Steiner, B., Lagache, T., Olivo-Marin, J.-C., Impens, F., Brodin, P., Hilbi, H., and Buchrieser, C. (2017). Legionella pneumophila Modulates Mitochondrial Dynamics to Trigger Metabolic Repurposing of Infected Macrophages. Cell Host Microbe 22, 302-316.e7.

Feltcher, M.E., Sullivan, J.T., and Braunstein, M. (2010). Protein export systems of Mycobacterium tuberculosis: novel targets for drug development? Future Microbiol 5, 1581-1597.

Garaude, J. (2019). Reprogramming of mitochondrial metabolism by innate immunity. Curr Opin Immunol 56, 17-23.

Garrido, C., Galluzzi, L., Brunet, M., Puig, P.E., Didelot, C., and Kroemer, G. (2006). Mechanisms of cytochrome c release from mitochondria. Cell Death Differ 13, 1423-1433.

Giraud-Gatineau, A., Coya, J.M., Maure, A., Biton, A., Thomson, M., Bernard, E.M., Marrec, J., Gutierrez, M.G., Larrouy-Maumus, G., Brosch, R., et al. (2020). The antibiotic bedaquiline activates host macrophage innate immune resistance to bacterial infection. ELife 9, e55692. 
Haydel, S.E., and Clark-Curtiss, J.E. (2004). Global expression analysis of two-component system regulator genes during Mycobacterium tuberculosis growth in human macrophages. FEMS Microbiol. Lett. 236, 341-347.

Hicks, S.W., and Galán, J.E. (2013). Exploitation of eukaryotic subcellular targeting mechanisms by bacterial effectors. Nat Rev Microbiol 11, 316-326.

Hmama, Z., Peña-Díaz, S., Joseph, S., and Av-Gay, Y. (2015). Immunoevasion and immunosuppression of the macrophage by Mycobacterium tuberculosis. Immunological Reviews 264, 220232.

Holm, L., and Rosenström, P. (2010). Dali server: conservation mapping in 3D. Nucleic Acids Res 38, W545-549.

Hua, Y., Yan, K., and Wan, C. (2018). Clever Cooperation: Interactions Between EspF and Host Proteins. Front. Microbiol. 9.

Jamwal, S., Midha, M.K., Verma, H.N., Basu, A., Rao, K.V.S., and Manivel, V. (2013). Characterizing virulence-specific perturbations in the mitochondrial function of macrophages infected with Mycobacterium tuberculosis. Sci Rep 3, 1328.

Jamwal, S.V., Mehrotra, P., Singh, A., Siddiqui, Z., Basu, A., and Rao, K.V.S. (2016). Mycobacterial escape from macrophage phagosomes to the cytoplasm represents an alternate adaptation mechanism. Scientific Reports 6, 23089.

Kostakioti, M., Newman, C.L., Thanassi, D.G., and Stathopoulos, C. (2005). Mechanisms of Protein Export across the Bacterial Outer Membrane. J Bacteriol 187, 4306-4314.

Lange, S., Rosenkrands, I., Stein, R., Andersen, P., Kaufmann, S.H.E., and Jungblut, P.R. (2014). Analysis of protein species differentiation among mycobacterial low-Mr-secreted proteins by narrow pH range Immobiline gel 2-DE-MALDI-MS. J Proteomics 97, 235-244.

Lee, J.-M., Cho, H.Y., Cho, H.J., Ko, I.-J., Park, S.W., Baik, H.-S., Oh, J.-H., Eom, C.-Y., Kim, Y.M., Kang, B.S., et al. (2008). O2- and NO-sensing mechanism through the DevSR two-component system in Mycobacterium smegmatis. J. Bacteriol. 190, 6795-6804.

Liang, Y., Zhang, X., Bai, X., Yang, Y., Gong, W., Wang, T., Ling, Y., Zhang, J., Wang, L., Wang, J., et al. (2019). Immunogenicity and Therapeutic Effects of Latency-Associated Genes in a Mycobacterium Tuberculosis Reactivation Mouse Model. Hum Gene Ther Methods 30, 60-69.

Luo, M., Zhou, W., Patel, H., Srivastava, A.P., Symersky, J., Bonar, M.M., Faraldo-Gómez, J.D., Liao, M., and Mueller, D.M. (2020). Bedaquiline inhibits the yeast and human mitochondrial ATP synthases. Communications Biology 3, 1-10.

Målen, H., Berven, F.S., Fladmark, K.E., and Wiker, H.G. (2007). Comprehensive analysis of exported proteins from Mycobacterium tuberculosis H37Rv. Proteomics 7, 1702-1718.

McGuffin, L.J., Bryson, K., and Jones, D.T. (2000). The PSIPRED protein structure prediction server. Bioinformatics 16, 404-405.

Mehrotra, P., Jamwal, S.V., Saquib, N., Sinha, N., Siddiqui, Z., Manivel, V., Chatterjee, S., and Rao, K.V.S. (2014). Pathogenicity of Mycobacterium tuberculosis is expressed by regulating metabolic thresholds of the host macrophage. PLoS Pathog. 10, e1004265.

Mohareer, K., Medikonda, J., Vadankula, G.R., and Banerjee, S. (2020). Mycobacterial Control of Host Mitochondria: Bioenergetic and Metabolic Changes Shaping Cell Fate and Infection Outcome. Front. Cell. Infect. Microbiol. 10. 
Müller-Taubenberger, A., Kortholt, A., and Eichinger, L. (2013). Simple system--substantial share: the use of Dictyostelium in cell biology and molecular medicine. Eur J Cell Biol 92, 45-53.

Nicholson, K.R., Mousseau, C.B., Champion, M.M., and Champion, P.A. (2021). The genetic proteome: Using genetics to inform the proteome of mycobacterial pathogens. PLOS Pathogens 17, e1009124.

Pan, F., Ye, T., Sun, P., Gui, S., Liang, B., Li, L., Zheng, D., Wang, J., Hesketh, R.L., Yang, L., et al. (2020). Time Course of Lung Changes On Chest CT During Recovery From 2019 Novel Coronavirus (COVID-19) Pneumonia. Radiology 200370-200370.

Penn, B.H., Netter, Z., Johnson, J.R., Von Dollen, J., Jang, G.M., Johnson, T., Ohol, Y.M., Maher, C., Bell, S.L., Geiger, K., et al. (2018). An Mtb-Human Protein-Protein Interaction Map Identifies a Switch between Host Antiviral and Antibacterial Responses. Mol Cell 71, 637-648.e5.

Perkowski, E.F., Zulauf, K.E., Weerakoon, D., Hayden, J.D., loerger, T.R., Oreper, D., Gomez, S.M., Sacchettini, J.C., and Braunstein, M. (2017). The EXIT Strategy: an Approach for Identifying Bacterial Proteins Exported during Host Infection. MBio 8.

Schnappinger, D., Schoolnik, G.K., and Ehrt, S. (2006). Expression profiling of host pathogen interactions: how Mycobacterium tuberculosis and the macrophage adapt to one another. Microbes Infect 8, 1132-1140.

Shi, L., Eugenin, E.A., and Subbian, S. (2016). Immunometabolism in Tuberculosis. Front Immunol 7, 150.

Shi, L., Jiang, Q., Bushkin, Y., Subbian, S., and Tyagi, S. (2019). Biphasic Dynamics of Macrophage Immunometabolism during Mycobacterium tuberculosis Infection. MBio 10.

Simeone, R., Bobard, A., Lippmann, J., Bitter, W., Majlessi, L., Brosch, R., and Enninga, J. (2012). Phagosomal rupture by Mycobacterium tuberculosis results in toxicity and host cell death. PLoS Pathog 8, e1002507.

Spier, A., Stavru, F., and Cossart, P. (2019). Interaction between Intracellular Bacterial Pathogens and Host Cell Mitochondria. Bacteria and Intracellularity 3-13.

Steinert, M. (2011). Pathogen-host interactions in Dictyostelium, Legionella, Mycobacterium and other pathogens. Semin Cell Dev Biol 22, 70-76.

Stridh, H., Kimland, M., Jones, D.P., Orrenius, S., and Hampton, M.B. (1998). Cytochrome c release and caspase activation in hydrogen peroxide- and tributyltin-induced apoptosis. FEBS Lett 429, 351-355.

Talaat, A.M., Lyons, R., Howard, S.T., and Johnston, S.A. (2004). The temporal expression profile of Mycobacterium tuberculosis infection in mice. Proc. Natl. Acad. Sci. U.S.A. 101, 4602-4607.

Troll, H., Malchow, D., Müller-Taubenberger, A., Humbel, B., Lottspeich, F., Ecke, M., Gerisch, G., Schmid, A., and Benz, R. (1992). Purification, functional characterization, and cDNA sequencing of mitochondrial porin from Dictyostelium discoideum. J Biol Chem 267, 21072-21079.

Turapov, O., Waddell, S.J., Burke, B., Glenn, S., Sarybaeva, A.A., Tudo, G., Labesse, G., Young, D.I., Young, M., Andrew, P.W., et al. (2014). Oleoyl coenzyme A regulates interaction of transcriptional regulator RaaS (Rv1219c) with DNA in mycobacteria. J Biol Chem 289, 25241-25249. 
Wilson, J.L., Mayr, H.K., and Weichhart, T. (2019). Metabolic Programming of Macrophages: Implications in the Pathogenesis of Granulomatous Disease. Front Immunol 10, 2265.

Winden, V.J.C. van, Houben, E.N.G., and Braunstein, M. (2019). Protein Export into and across the Atypical Diderm Cell Envelope of Mycobacteria. Microbiology Spectrum 7.

Ye, Y., and Godzik, A. (2004). Database searching by flexible protein structure alignment. Protein Sci 13, 1841-1850.

Zahrt, T.C., and Deretic, V. (2001). Mycobacterium tuberculosis signal transduction system required for persistent infections. PNAS 98, 12706-12711.

\section{FIGURE LEGENDS}

Fig. 1 Rv1813c defines a new protein family (A) M. tuberculosis and M. marinum Rv1813c homologues sequence alignments. The conservation between the members is high for the folded domain (secondary structure of the Rv1813c structure are reported above the alignment). The Nterminal unfolded domain is less conserved and seems to define two subclasses. The yellow numbers indicate the cysteine engaged in disulfide bridges. (B) Rv1813c structure determined by multi-dimensional NMR. Three cartoon representations of the structure. Only 4 residues of Nterminal unfolded part of the protein (residues 28-57) are represented. The cysteine residues, all engaged in disulfide bridges are represented in yellow while the two solvent-exposed tryptophans are represented in orange.

\section{Fig. 2 Rv1813c is secreted by Mtb in broth culture}

Rv1813 is detected in M. tuberculosis culture filtrate but not in cellular fractions. Lysate obtained from M. tuberculosis H37Rv strain grown in Sauton's medium to logarithmic phase $\left(\mathrm{OD}_{580} \sim 0.7\right)$ were fractionated and probed with anti-Rv1813 polyclonal antibodies. Culture filtrates were obtained from the same culture. Anti-FtsZ (FtsZ is a cytoplasmic protein), anti-GInA (GInA is a membrane protein) and anti-RpfB (RpfB is a membrane and cell-wall anchored protein) antibodies were used to confirm the purity of mycobacterial fractions.

\section{Fig. 3 Mitochondrial localisation of Rv1813c in Dictyostelium.}

Dictyostelium cells expressing the indicated constructs were fixed, processed for immunofluorescence, and analyzed by confocal microscopy (Airyscan). (A) myc-Rv1813c detected with a rabbit polyclonal to Rv1813c colocalises with mitochondrial Mitoporin in ring shaped structures. (B) Rv1813c is mostly excluded from the inside of mitochondria labeled with the Mitotracker deep red dye. Close up of mitochondria are shown in the insert. (C) The Rv1813c folded domain alone is efficiently targeted to mitochondria. Maximum projection of $Z$ confocal sections of the full-length 
protein (myc-Rv1813c), the sole structured (myc-Rv1813c_49-143) and the unfolded domain (mycRv1813c_28-56) labeled with an anti-myc antibody. Cell contour is indicated by dotted lines. Bar, $5 \mu \mathrm{m}$.

Fig. 4 Biochemical analysis of Rv1813c mitochondrial localization and functional consequences

(A) Fractionation scheme of differential centrifugation steps used to purify the Rv1813c enriched fraction. (B) Fractions were analyzed by immunoblotting with antibody to Mitoporin (mitochondria), EHD (endocytic vacuoles) and myc-tag (myc-Rv1813c). Rv1813c concentrates into the mitochondrial enriched fraction P1. (C) The mitochondrial fraction was fractionated by Triton X114 extraction. The separated Triton X-114 (TX) and aqueous (W) phases were analyzed as above. Rv1813c is not extracted by Triton X-114 indicating no insertion inside membranes. (D) Mitochondria were incubated in sodium carbonate for $30 \mathrm{~min}$. Rv1813c is mainly detected in the supernatant fraction (S) after centrifugation at $100,000 \mathrm{~g}$ of treated mitochondria, a characteristic of soluble and/or membrane peripheral proteins. (E) Mitochondria were incubated in buffer $\pm 200 \mathrm{mM} \mathrm{KCl}$ for 30 min and centrifuged at $16,000 \mathrm{~g}$ for $10 \mathrm{~min}$. Rv1813c stays in P1 indicating that no washing out from mitochondria by this treatment. (F) Intact or Triton X100 treated mitochondria were subjected to proteinase $\mathrm{K}$ digestion for $30 \mathrm{~min}$ and analyzed by immunoblotting. In intact mitochondria, Rv1813c is protected from proteinase $\mathrm{K}$ digestion but sensitive to this treatment in presence of detergent consistent with an intra-mitochondrial localization. (G) Mitochondria swelling was induced by hypotonic buffer incubation for $30 \mathrm{~min}$. Released proteins from broken outer membranes were recovered by centrifugation at $16,000 \mathrm{~g}$ for $10 \mathrm{~min}$ and analyzed by western blotting. Rv1813c is equally distributed in P1 and S1 fractions indicating localization both on internal mitochondrial membranes and in the IMS. (H) Analysis of mitochondrial membrane potential by flow cytometry of JC-1 stained cells. JC-1 Red/Green ratio were calculated and expressed as the \% of this ratio in recipient cells (Ax2). Rv1813c expression increases the mitochondrial membrane potential as revealed by an elevated JC-1 Red/Green ratio. Values are means \pm s.e.m. of three independent experiments. (I) Analysis of mitochondrial ROS production by flow cytometry of MitoSox stained cells. MitoSox fluorescence was expressed as the \% of fluorescence in recipient cells (Ax2). No modification of mitochondrial ROS production is observed upon Rv1813c expression. Values are means \pm s.e.m. of three independent experiments. (J) Phase contrast microscopy of wild type (Ax2) or Rv1813c expressing cells (Ax2 + myc-Rv1813c) incubated in $0.4 \mathrm{mM}$ hydrogen peroxide for 4 hours. White arrows indicate cellular debris. Bar, $10 \mu \mathrm{m}$. (K) Graph of cell viability observed after hydrogen peroxide treatment for 4 hours determined by FACS analysis upon Propidium lodide staining of dead cells. Rv1813c increases cell sensitivity to oxidative stress. Values are means \pm s.e.m. of four independent experiments. 
Fig. 5 Targeting of Rv1813c to mitochondria in mammalian cells

(A) Confocal microscopy analysis of HeLa cells transiently expressing myc-Rv1813. Cells were fixed 48h post-transfection, processed for immunofluorescence, and analyzed by Airyscan microscopy. myc-Rv1813c was detected by a polyclonal antibody to RV1813c and shows strict colocalization with mitochondrial Cytochrome c. Bar, $10 \mu \mathrm{m}$. (B) Quantitative analysis of mitochondria morphology in HeLa cells transiently transfected with pCl-myc-Rv1813 or empty vector. Mitochondria morphology was manually identified by confocal microscopy and classified in one hundred cells. Rv1813c expressing cells exhibit a normal mitochondrial morphology. (C) Schematic ultrastructure of a single crista in mitochondria. (D, E) Representative mitochondria ultrastructure determined by transmission electronic microscopy of MACS enriched HeLa cells transiently transfected with pMACS-4-IRES-II Rv1813c (D) or vector alone (E). Black arrows indicate some enlarged intra-cristae spaces in Rv1813c expressing cells. Spaces between adjacent cristae are enlarged upon Rv1813c overexpression. Bars, $500 \mathrm{~nm}$. (F) Bar graph of intra-cristae spaces measurements for the indicated cell lines (100 random measurements each, ${ }^{\star \star \star \star} p<0.0001$ in student test).

\section{Fig. 6 Functional consequences of Rv1813c mitochondrial localisation}

(A) Rv1813c expression enhances cell respiratory functions. HeLa cells were transiently transfected with pMACS-4-IRES-II Rv1813c or vector alone and enriched to >94\% through a double magnetic cell sorting (MACS) procedure (see experimental section). Cell respiratory profiles (OCR) were obtained using an extracellular flux analyser (Seahorse XF analyzer) and the mitochondrial respiration test. After reaching basal respiration, cells were subjected to $1 \mu \mathrm{M}$ oligomycin to inhibit the ATP synthase and measure the mitochondrial ATP-linked OCR, followed by $1 \mu \mathrm{M}$ FCCP (cyanide-4-[trifluoromethoxy]phenylhydrazone) to uncouple mitochondrial respiration and maximize OCR, and finally $1 \mu \mathrm{M}$ antimycin A and 100nM rotenone to inhibit complex III and I in the ETC respectively, and shut down respiration. In Rv1813c transfected cells, basal respiration, ATP-linked respiration, maximal respiratory capacity and reserve capacity are significantly increased compared to native HeLa cells. (B) Analysis of glycolytic functions. Extracellular acidification (ECAR) profiles of the same MACS enriched transfected cells were determined simultaneously to OCR analysis using the glycolysis stress test and the XF analyzer. After reaching non-glycolytic acidification, $10 \mathrm{mM}$ glucose was added, followed by $1 \mu \mathrm{M}$ oligomycin to inhibit the ATP synthase and induce maximal glycolysis. Finally, 100 mM 2-deoxyglucose (2-DG) was added to shut down glycolysis. 
This last injection resulted in a decreased ECAR confirming that the recorded ECAR was only due to glycolysis. Rv1813c expressing cells and native Hela show similar in ECAR profiles.

In (C) and (D), HeLa cells were transiently transfected with pCl-myc-Rv1813c or empty vector and analyzed $48 \mathrm{~h}$ later by flow cytometry (C) Flow cytometry analysis of $\mathrm{JC}-1$ stained cells to monitor mitochondrial membrane potential. JC-1 Red/Green ratio were calculated and expressed as the \% of this ratio in HeLa cells. Values are means \pm s.e.m. of three independent experiments. ns, not significantly different Student's t-test. In contrast to Dictyostelium, the mitochondrial membrane potential is not enhanced in HeLa cells transiently expressing Rv1813c (D) Flow cytometry analysis of MitoSox stained cells. MitoSox fluorescence was expressed as the \% of fluorescence in HeLa cells. Mitochondrial ROS production is slightly increased upon Rv1813c expression. Values are means \pm s.e.m. of three independent experiments, ${ }^{* \star} p \leq 0.01$ Student's t-test.

In (E) and (F), HEK293T cells were transiently transfected with pCl-myc-Rv1813c or empty vector and analyzed $48 \mathrm{~h}$ later by flow cytometry (E) Cell death analysis by flow cytometry of cells treated with $0.15 \mathrm{mM}$ hydrogen peroxide for $8 \mathrm{~h}$ and $24 \mathrm{~h}$ and stained with Annexin $\mathrm{V}$ and propidium iodide (PI). Early apoptosis is characterized by no PI labeling but Annexin V cell staining due to the translocation of phosphatidylserine (PS) from the inner face of the plasma membrane to the cell surface and. In contrast, late apoptosis and necrosis results in both Annexin V and PI positive staining. Percentage of each characteristic population is indicated. Flow graphs are representative of three independent experiments. (F) Quantification of Annexin V fluorescence in cells treated with increasing amount of hydrogen peroxide for $24 \mathrm{~h}$ shows that Rv1813c promotes cell death in response to prolonged oxidative stress. Cells were analyzed as described in (E). Annexin $V$ positive cells include PI negative and positive stained cells. Values are means \pm s.e.m. of three independent experiments, ${ }^{* *} p \leq 0.01$ Student's t-test.

Fig. 7 Defective Cyt-c release from mitochondria upon oxidative stress and massive Rv1813c egress to the cytosol.

(A) Confocal microscopy analysis of HeLa cells transiently expressing myc-Rv1813.

$48 \mathrm{~h}$ post-transfection, cells were treated with 0.1 or $0.2 \mathrm{mM}$ hydrogen peroxide for three hours, fixed, processed for immunofluorescence with anti-Cytochrome c (green) and anti-Rv1813c (red) antibodies, and observed by confocal microscopy. Nuclei were stained with Hoechst (blue). White arrows and white stars indicate cells with Cyt-c in mitochondria and cytosol respectively. Cyt-c shows a diffuse cytosolic staining in $21 \%$ of HeLa cells submitted to a moderate oxidative stress ( $0.1 \mathrm{mM}$ hydrogen peroxide). This effect is dose dependent, rising up to $25.7 \%$ at $0.2 \mathrm{mM}$ hydrogen peroxide. In contrast, Cyt-c translocation into the cytosol is highly reduced in cells overexpressing Rv1813c, with only $7.9 \%$ of cells displaying a cytosolic Cyt-c staining upon $0.1 \mathrm{mM}$ hydrogen peroxide treatment. Scale bar, $10 \mu \mathrm{m}$ (B, C, D) Quantification of cells with Cyt-c in cytosol 
(B), with Rv1813c in cytosol (C) and Rv1813c in cytosol but Cyt-c in mitochondria (D) upon incubation with hydrogen peroxide for three hours. Oxydative stress induces a massive exit of Rv1813c from mitochondria and a subsequent partial inhibition of Cyt-c release in the cytosol. Values are means \pm s.e.m. of three independent experiments, with 100 cells analyzed for each condition, * $\mathrm{p}<0.05$ Student's t-test.

\section{SUPPLEMENTARY DATA LEGENDS}

\section{Fig. $S 1{ }^{1} \mathrm{H}-{ }^{15} \mathrm{~N}$ HSQC spectrum of Rv1813c}

This spectrum was obtained at $800 \mathrm{MHz}, 20^{\circ} \mathrm{C}$ and $\mathrm{pH} 6,8$ with $0.3 \mathrm{mM}{ }^{15} \mathrm{~N}$-uniformly labeled sample. Cross peak assignments are indicated using the one-letter amino acid code and number following the full-length protein sequence numbering.

Fig. S2 Confocal microscopy analysis of Rv1813c family members localisation in Dictyostelium.

Dictyostelium cells expressing the indicated constructs were fixed, processed for immunofluorescence, and analyzed by confocal microscopy (Airyscan).

(A) Mitochondrial localisation of untagged Rv1813c expressed in Dictyostelium. Rv1813c was labeled with a rabbit pAb anti-Rv1813c antibody. Rv1813c colocalises with Mitoporin, a mitochondrial specific protein.

(B) Mitoporin localisation in untransfected recipient Ax2 cells. Cells were labeled with a mouse mAb to mitoporin revealing characteristic ring shaped structures. A maximum projection of $Z$ confocal sections is shown on the right panel.

(C) Localization of different Rv1813c family members of $M$. tuberculosis and $M$. marinum expressed in Dictyostelium and revealed by anti-myc labelling. Whereas $M$. marinum orthologs of Rv1813c (MMA_1436 and MMA_2533) are addressed to mitochondria without any major morphological effects, Rv1269c and its ortholog MMA_4153 localization to mitochondria induces mitochondria morphological defects. White arrows indicate so mitochondria with affected shapes. Bar, $5 \mu \mathrm{m}$.

\section{Fig. S3 Rv1813c family localisation in HeLa cells}

HeLa cells expressing the indicated constructs were fixed, processed for immunofluorescence, and analyzed by confocal microscopy (Airyscan).

Cells were colabeled either with rabbit polyclonal anti-Rv1813c, mouse mAb anti-Cytochrome c, and mitotracker deep red (upper panel) or anti-myc, rabbit anti-grp75 (mitochondria marker) and mitotracker deep red (lower panels). Rv1813c and its M. marinum orthologs (MMA_1426 and 
MMA_2533) are efficiently addressed to mitochondria in contrast to Rv1269c and its ortholog MMA_4153. Bar, $10 \mu \mathrm{m}$.

\section{Fig. S4 Rv1813c family localization in HEK293 cells}

HEK293 cells expressing the indicated constructs were fixed, processed for immunofluorescence, and analyzed by confocal microscopy (Airyscan).

Cells were labeled as described in Fig. S4. Rv1813c family members are targeted to mitochondria in HEK293. As observed in HeLa cells, Rv1269c is barely detectable in mitochondria whereas some faint mitochondrial staining is observed with MM_4153 expressed in HEK293. Bar, $10 \mu \mathrm{m}$.

\section{Fig. S5 Mitochondrial ultrastructure in HEK293 expressing Rv1813c}

Representative mitochondria ultrastructure determined by transmission electronic microscopy of HEK293 cells transiently transfected with Rv1813c (right panel) or vector alone (left panel). Black arrows indicate some enlarged intra-cristae spaces in Rv1813c expressing cells. Bars, $500 \mathrm{~nm}$. 


\section{SUPPLEMENTARY TABLE 1}

NMR and refinement statistics for RV1813 protein structures

\section{NMR distance and dihedral constraints}

\section{Distance constraints}

Total NOE

Intra-residue

Inter-residue

Sequential $(|i-j|=1)$

Medium-range $(|i-j|<4)$

Long-range $(|i-j|>5)$

Hydrogen bonds

Total dihedral angle restraints

$\phi$

$\psi$
1516

406

465

253

392

84

82

82

\section{Structure statistics}

Violations (mean and s.d.)

Max. distance constraint violation $(\AA) \quad 0.18 \pm 0.03$

Max. dihedral angle violation $\left(^{\circ}\right)$

Deviations from idealized geometry

Bond lengths $(\AA)$

$2.04 \pm 0.48$

Bond angles $\left({ }^{\circ}\right)$

$0.0118 \pm 0.0002$

Impropers $\left(^{\circ}\right)$

$1.2010 \pm 0.0214$

$1.3446 \pm 0.0861$

\section{Ramachandran plot (\%)}

Most favoured region

84.7

Additionally allowed region

14.2

Generously allowed region

0.8

Disallowed region

0.3

Average pairwise r.m.s. deviation ${ }^{\star \star}(\AA)$

Backbone

$0.66 \pm 0.18$

Heavy

$1.26 \pm 0.19$

** "Pairwise r.m.s. deviation calculated among 20 refined structures for residues 31-116." 


\section{Supplementary Materials and methods}

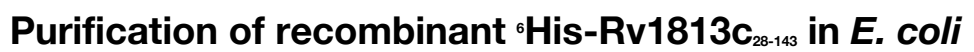

E. coli BL21(DE3) strains containing pET::rv1813 $3_{28-143}$ vector were used to inoculate $1 \mathrm{~L}$ of LB medium supplemented with ampicillin $(100 \mu \mathrm{g} / \mathrm{ml})$ and resulting cultures were incubated at $37^{\circ} \mathrm{C}$ with shaking until $A_{600}$ reached $\sim 0.5$. Then, $1 \mathrm{mM}$ final of isopropyl 1-thio- $\beta$ - $d$-galactopyranoside was added and growth was continued for $3 \mathrm{hr}$ at $37^{\circ} \mathrm{C}$. The cells were harvested by centrifugation and the resulting cell pellet was resuspended in buffer $\mathrm{A}$ ( $50 \mathrm{mM}$ Tris-HCl pH 8.5, $150 \mathrm{mM} \mathrm{NaCl}, 2 \mathrm{mM}$ DTT). Cells were then lysed by sonication and cell debris and insoluble materials were separated by centrifugation. The pellet was then resuspended in buffer B (Buffer A + 8M Urea). After centrifugation the supernatant was loaded into a Hitrap ${ }^{\text {тм }}$ IMAC HP column (Amersham biosciences), equilibrated in buffer B and $4 \%$ of buffer C (buffer B supplemented with $300 \mathrm{mM}$ of imidazole). The column was washed with successive applications of buffer B (approximately $30 \mathrm{ml}$ in total) to remove all the impurities and then buffer $\mathrm{C}$ was increased over $20 \mathrm{ml}$ to $100 \%$. Fractions containing the Rv1813c proteins were identified by SDS-PAGE, then pooled and concentrated using a $5 \mathrm{~K}$ cut-off concentrator to a $2 \mathrm{mg} / \mathrm{ml}$ concentration. The protein was dialysed against buffer A over-night at $4^{\circ} \mathrm{C}$. The refolded protein was very unstable until removal of the $6 \mathrm{His}$ tag using $3 \mathrm{C}$ protease (4h digestion at $4^{\circ} \mathrm{C}$ ). The protein was then loaded to a Superdex 75 26/60 (Amersham biosciences) size exclusion column, equilibrated in buffer $20 \mathrm{mM} \mathrm{Na-Phosphate} \mathrm{pH}$ 6.2, $150 \mathrm{mM} \mathrm{NaCl}$. Again, fractions containing the protein were identified by SDS-PAGE, then pooled and stored at $-20^{\circ} \mathrm{C}$ until required. This protocol was carried out for all the non-labelled constructs of Rv1813c as well as for ${ }^{15} \mathrm{~N}$ and ${ }^{15} \mathrm{~N}-{ }^{13} \mathrm{C}$ labelled constructs, except that the cultures were grown in a minimum media containing ${ }^{15} \mathrm{NH}_{4} \mathrm{Cl}$ and ${ }^{15} \mathrm{NH}_{4} \mathrm{Cl} /{ }^{13} \mathrm{C} 6$-glucose as the sole nitrogen and carbon sources.

\section{Solution structure of $\mathrm{Rv} 1813 \mathrm{c}_{20-13}$}

All NMR experiments were generally carried out at $25^{\circ} \mathrm{C}$ on Bruker Avance III $700\left({ }^{1} \mathrm{H}-{ }^{15} \mathrm{~N}\right.$ double resonance experiments) or Avance III $500\left({ }^{1} \mathrm{H}-{ }^{13} \mathrm{C}-{ }^{-15} \mathrm{~N}\right.$ triple-resonance experiments) spectrometer equipped with $5 \mathrm{~mm}$ z-gradient TCl cryoprobe, using the standard pulse sequences. NMR samples consist of approximately $0.9 \mathrm{mM}{ }^{15} \mathrm{~N}$ - or ${ }^{15} \mathrm{~N},{ }^{13} \mathrm{C}$-labeled protein dissolved in $25 \mathrm{mM}$ NaCitrate, 150 $\mathrm{mM} \mathrm{NaCl}(\mathrm{pH} 5.6)$ with $10 \% \mathrm{D}_{2} \mathrm{O}$ for the lock. ${ }^{1} \mathrm{H}$ chemical shifts were directly referenced to the methyl resonance of DSS, while ${ }^{13} \mathrm{C}$ and ${ }^{15} \mathrm{~N}$ chemical shifts were referenced indirectly to the absolute ${ }^{15} \mathrm{~N} /{ }^{1} \mathrm{H}$ or ${ }^{13} \mathrm{C} / 1 \mathrm{H}$ frequency ratios. All NMR spectra were processed and analyzed with GIFA. Backbone and $\mathrm{C} \beta$ resonance assignments were made using standard $\mathrm{HNCA}, \mathrm{HNCACB}, \mathrm{CBCA}(\mathrm{CO}) \mathrm{NH}$, $\mathrm{HNCO}$, and $\mathrm{HN}(\mathrm{CA}) \mathrm{CO}$ experiments performed on the ${ }^{15} \mathrm{~N},{ }^{13} \mathrm{C}$-labeled $\mathrm{Rv} 1813 \mathrm{C}{ }^{28-143}$ sample. NOE cross-peaks identified on 3D [ $\left.\mathrm{H},{ }^{15} \mathrm{~N}\right] \mathrm{NOESY}-\mathrm{HSQC}$ (mixing time $120 \mathrm{~ms}$ ) were assigned through automated NMR structure calculations with CYANA 2.1, whereas NOE on 3D $\left[{ }^{1} \mathrm{H},{ }^{13} \mathrm{C}\right]$ NOESY-HSQC 
were assigned manually. Backbone $\phi$ and $\psi$ torsion angle constraints were obtained from a database search procedure on the basis of backbone $\left({ }^{15} \mathrm{~N}, \mathrm{H}_{\mathrm{N}},{ }^{13} \mathrm{C},,{ }^{13} \mathrm{Ca}, \mathrm{Ha},{ }^{13} \mathrm{C} \beta\right)$ chemical shifts using the program TALOS+ (Shen et al., 2009). Hydrogen bond restraints were derived using standard criteria on the basis of the amide ${ }^{1} \mathrm{H} /{ }^{2} \mathrm{H}$ exchange experiments and NOE data. When identified, the hydrogen bond was enforced using the following restraints: ranges of $1.8-2.0 \AA$ for $\mathrm{d}(\mathrm{N}-\mathrm{H}, \mathrm{O})$, and 2.7-3.0 $\AA$ for $d(N, O)$. The final list of restraints, from which values redundant with the covalent geometry has been eliminated. The 30 best structures (based on the final target penalty function values) were minimized with CNS 1.2 according the RECOORD procedure (Nederveen et al., 2005) and analyzed with PROCHECK (Laskowski et al., 1993). The rmsds were calculated with MOLMOL (Koradi et al., 1996). All statistics are given in Table 1. The chemical shift table was deposited in the BMRB databank (accession number XXX) and the coordinates have been deposited in the PDB: PDBXXX.

\section{Antibodies}

The following primary antibodies were used in this study: mouse anti-Myc (Invitrogen, \#13-2500, 1:200 for immunofluorescence, 1:500 for immunoblot), mouse anti-cytochrome c (clone 6H2.B4, BD PharMingen, 1:500 for immunofluorescence), mouse anti-Dictyostelium Mitoporin (70-100-1; 1:2000 for immunofluorescence and immunoblot) (Troll et al., 1992), rabbit anti-Rv1813c raised using recombinant Rv1813c (ProteoGenix SAS, Schiltigheim, France) (1:2000 for immunofluorescence, 1:5000 for immunoblot), rabbit anti-Grp75 (D13H4, XP \#3593, Cell Signalling, 1:100 for immunofluorescence), rabbit anti-EHD (Dias et al., 2012; 1:4000 for immunoblot). Secondary antibodies used for immunoblotting were horseradish peroxidase (HRP)-conjugated donkey anti-mouse $\operatorname{lgG}(\mathrm{H}+\mathrm{L})$ (\#715-035-151) and HRP-conjugated donkey anti-rabbit lgG (H+L) (\#715-035-152) (Jackson ImmunoResearch). Secondary antibodies used for immunofluorescence were Alexa-Fluor-568conjugated goat anti-mouse IgG $(\mathrm{H}+\mathrm{L})$ (\#A11031), Alexa-Fluor-594-conjugated donkey anti-rabbit $\lg \mathrm{G}(\mathrm{H}+\mathrm{L})(\# A 21207)$, Alexa-Fluor-488-conjugated goat anti-rabbit IgG $(\mathrm{H}+\mathrm{L})(\# A 11029)$ and AlexaFluor-488-conjugated donkey anti-rabbit IgG (H+L) (\#A21206) (ThermoFisher Scientific, Illkirsh, France). All secondary antibodies were used at 1:500 for immunofluorescence. Prolong Golf Antifade and Hoechst 33342 (\#62249) were purchased from Molecular Probes (ThermoFisher Scientific, Illkirsh, France).

\section{Preparation of Mycobacterium tuberculosis culture}

M. tuberculosis was grown in Middlebrook $7 \mathrm{H} 9$ liquid medium supplemented with $10 \%$ (v/v) Albumin-Dextrose Complex (ADC), $0.2 \%(\mathrm{v} / \mathrm{v})$ glycerol and $0.1 \%$ Tween $80(\mathrm{w} / \mathrm{v})$, at $37^{\circ} \mathrm{C}$ in a roller incubator. Bacterial growth was followed by measurement of absorbance at $580 \mathrm{~nm}$, using a spectrophotometer, or by colony-forming unit (CFU) counting on $7 \mathrm{H} 10$ agar. 


\section{Mycobacterial cell fractionation}

Mycobacteria cell fractionation was done as described else were (O.Turapov, Cell Report, 2018). Briefly, cells were lysed in a buffer that contained $20 \mathrm{mM}$ TrisHCl, pH 8.0, $150 \mathrm{mM} \mathrm{NaCl}, 20 \mathrm{mM}$ $\mathrm{KCl}, 10 \mathrm{mM} \mathrm{MgCl}$. Bacterial culture was homogenized with a Minilys homogenizer (Bertin Instruments) using glass beads. A cocktail of proteinase/phosphatase inhibitors (Roche, UK) were used in all buffers. Lysates were centrifuged for 1 hour at 27,000 x g, the pellets were washed in a carbonate buffer $(\mathrm{pH} 11)$ and used as a cell wall material. The supernatant was centrifuged again for 4 hours at $100,000 \times \mathrm{g}$. The supernatants from this step was used as cytoplasmic fraction and the pellets (membrane fractions) were washed once in carbonate buffer, $\mathrm{pH} 11$ and twice in TBS buffer. Proteins from cellular fractions were separated on SDS-PAGE. The purity of fractions was confirmed by the detection of diagnostic proteins as described below.

\section{Protein Electrophoresis and Western Blot}

Proteins were separated on $4 \%-20 \%$ gradient SERVA gels and transferred onto a nitrocellulose membrane using a Trans-Blot $®$ Turbo Transfer System (Bio-Rad) according to the manufacturer's instruction. SignalFire Elite ECL Reagent (Cell Signalling, UK) were used to visualize proteins on CDiGit Chemiluminescent Blot Scanner (LI-COR Biosciences), according to the manufacturer's instructions. All the secondary antibody were from Cell Signalling, UK. Diagnostic proteins were used for all the cellular fractions: GlnA (membrane protein), RpfB (membrane and cell wall protein) and FtsZ was used as a cytoplasmic fractions marker.

\section{Cell culture and transfection conditions}

D. discoideum strain Ax2 was grown at $22^{\circ} \mathrm{C}$ in $\mathrm{HL} 5 \mathrm{c}$ medium supplemented with $18 \mathrm{~g} / \mathrm{L}$ Maltose (Formedium, Norfolk, United Kingdom). For ectopic expression in Dictyostelium, Rv1813c family coding sequences with Dictyostelium optimized codons (IDT, Integrated DNA Technologies, Inc., Coralville, lowa 5224, USA) were cloned into pDXA-3C-myc (Manstein et al., 1995). Plasmids were linearized by Scal and transfected by electroporation as described (Cornillon et al., 2000). Clones were selected in $5 \mu \mathrm{g} / \mathrm{mL}$ G418.

HeLa (ATCC CRM-CCL-2) and HEK-293T (ATCC CRL-3216) cells were maintained in DMEM, high glucose (Dulbecco's Modified Eagle Medium) containing 5\% and 10\% heat-inactivated foetal bovine serum, respectively, and supplemented with GlutaMAX ${ }^{\mathrm{TM}}$ (Gibco Life Technologies), penicillin (100 units $/ \mathrm{mL})$, and streptomycin $(100 \mu \mathrm{g} / \mathrm{mL})$. Transfections of HeLa and HEK-293T cells were performed using JetPEl ${ }^{\text {тм }}$ transfection reagent (PolyPlus-Transfection, Ozyme, Saint Quentin, France), according to the manufacturer. Cells plated one day before transfection were incubated with JetPEl ${ }^{\mathrm{T}}$-DNA complexes $(\mathrm{N} / \mathrm{P}=5)$, and after $5 \mathrm{~h}$ the medium was changed. All assays were performed $48 \mathrm{~h}$ post-transfection. 
For confocal microscopy analysis, HeLa or HEK-293T cells were seeded on glass coverslips coated with $0.001 \%$ poly-L-Lysine (\# P4707, Sigma). For localization, Rv1813c family coding sequences with human optimized codons were cloned into the mammalian expression vector $\mathrm{pCl}$ (a kind gift of Dr. Solange Desagher, IGMM, Montpellier, France). Cells on glass coverslips were transfected in a 24-well culture plate and analysed $48 \mathrm{~h}$ later. For mitochondrial membrane potential, mitochondrial ROS and oxidative stress studies, cells were transfected on 6 -well culture plates. After $24 \mathrm{~h}$, resuspended cells were pooled and plated either on glass coverslips for confocal microscopy or on 6well culture plates at a density of $2-3.10^{5} \mathrm{cells} /$ well for FACS analysis. For extracellular flux analysis, HeLa cells seeded into five 100-mm tissue culture dishes were transfected with Rv1813c DNA cloned into pMACS 4-IRESII vector (Miltenyi Biotec, France), allowing Rv1813c co-expression with a truncated CD4 surface marker. After 24h, EDTA resuspended cells were pooled and CD4 positive cells selected through magnetic cell sorting (MACS) (see below).

\section{Mitochondria isolation and biochemical treatments}

Mitochondria were isolated as described (Aubry and Klein, 2006). Briefly Dictyostelium cells were washed in ice-cold buffer A (20 mM HEPES pH7, 1 mM EDTA, 250 mM Sucrose, proteinase inhibitors), resuspended at a cell density of $3 \times 10^{8}$ cells $/ \mathrm{mL}$, and broken with a ball bearing homogenizer (8.02 mm bore, $8.002 \mathrm{~mm}$ ball; 20 strokes). Unbroken cells were removed by low speed centrifugation $(5 \mathrm{~min}, 1500 \mathrm{~g}$ ). The supernatant was next centrifuged for $15 \mathrm{~min}$ at 16,000 g. The pellet was resuspended in buffer $A$ and the centrifugation repeated to yield the enriched mitochondria fraction. For further subcellular fractionation, this fraction was further centrifuged at $100,000 \mathrm{~g}$ for $1 \mathrm{~h}$. Triton X-114 phase fractionation was performed as described (Bordier, 1981). Briefly, mitochondria were incubated for $20 \mathrm{~min}$ at $4{ }^{\circ} \mathrm{C}$ in $10 \mathrm{mM}$ Tris- $\mathrm{HCl} \mathrm{pH7.4,150} \mathrm{mM} \mathrm{NaCl}$ and $1 \%$ Triton $\mathrm{X}-114$. Samples were loaded on a $6 \%$ sucrose cushion, incubated at $30^{\circ} \mathrm{C}$ for 3 min for condensation, and centrifuged at $300 \mathrm{~g}$ for $3 \mathrm{~min}$ at room temperature. Supernatants were adjusted to $1 \%$ Triton X-114 and the procedure repeated. Detergent and aqueous phases were analysed by western blotting.

For Carbonate extraction of integral membrane proteins, mitochondria were incubated for $30 \mathrm{~min}$ at $4{ }^{\circ} \mathrm{C}$ in $0.1 \mathrm{M} \mathrm{Na}_{2} \mathrm{CO}_{3} \mathrm{pH} 11.5$ and centrifuged for $30 \mathrm{~min}$ at 100,000 g. Pellets were resuspended in buffer A. Proteins in resuspended pellets and supernatants were precipitated with 15\% TCA and resuspended in SDS page loading buffer. For high salt washes, intact mitochondria were incubated in $10 \mathrm{mM}$ Tris- $\mathrm{HCl}$ pH7.3, $250 \mathrm{mM}$ Sucrose, $200 \mathrm{mM} \mathrm{KCl}$ and incubated for $30 \mathrm{~min}$ at $4^{\circ} \mathrm{C}$. Mitochondria were then centrifuged for $10 \mathrm{~min}$ at 16,000 g. Pellets and supernatants were treated as above. For proteinase $\mathrm{K}$ digestions of mitochondrial peripheral membrane proteins, mitochondria in $20 \mathrm{mM}$ HEPES pH7, $250 \mathrm{mM}$ Sucrose, $100 \mathrm{mM} \mathrm{KCl,} 2 \mathrm{mM} \mathrm{MgCl}_{2}, 1 \mathrm{mM} \mathrm{KH}_{2} \mathrm{PO}_{4}$ were incubated with $100 \mu \mathrm{g} / \mathrm{mL}$ proteinase $\mathrm{K}$ for $30 \mathrm{~min}$ at $4^{\circ} \mathrm{C} \pm 1 \%$ Triton $\mathrm{X} 100$. Samples were then treated with TCA for protein precipitation. To break selectively mitochondrial outer membranes, mitochondria were resuspended in hypotonic buffer ( $2 \mathrm{mM} \mathrm{HEPES} \mathrm{pH7,} 5 \mathrm{mM} \mathrm{KCL}$, proteinase inhibitors) for 30 
min at room temperature. After centrifugation at $16,000 \mathrm{~g}$ for $10 \mathrm{~min}$, pellets and supernatants were treated with TCA as above.

\section{Immunocytochemistry}

Dictyostelium cells were applied on glass coverslips for $3 \mathrm{~h}$, and then fixed with $4 \%$ paraformaldehyde for $30 \mathrm{~min}$, washed and permeabilized for $2 \mathrm{~min}$ in $-20^{\circ} \mathrm{C}$ methanol. Cells were incubated with the indicated antibodies for $1 \mathrm{~h}$, washed, and then stained with appropriate fluorescent secondary antibodies for $30 \mathrm{~min}$. After three washes, coverslips were mounted in Mowiol. Mammalian cells were cultured on glass coverslips and fixed with $4 \%$ paraformaldehyde in phosphate-buffered saline (PBS) for $20 \mathrm{~min}$. Cells were washed in Tris-buffered saline (TS; $25 \mathrm{mM}$ Tris pH7.4, 150mM NaCl) for 10 min. After permeabilization with $0.2 \%$ Triton X-100 in TS for 4 min, non-specific binding was blocked with $0.2 \%$ gelatin from cold water fish skin (Sigma-Aldrich, France) in TS for 30 min. Cells were incubated with primary antibodies in blocking buffer for $1 \mathrm{~h}$ and were then washed 3 times with $0.008 \%$ TritonX-100 in TS for 10 minutes. Cells were incubated for 30 minutes with AlexaFluor-labelled secondary antibodies in blocking buffer. After rinsing in washing buffer, cell nuclei were stained with $1 \mu \mathrm{g} / \mathrm{ml}$ Hoechst in TS for 5 minutes. Finally, coverslips were mounted with Prolong Gold Antifade (\#P36934 Thermo Fisher Scientific). Slides were examined under a Leica TCS SPE confocal microscope equipped with a 40X/1.15 or 63X/1.33 ACS APO oil-immersion objective or a Zeiss LSM880 AiryScan confocal microscope equipped with a 40X/1.4 or 63x/1.4 Oil Planapochromat DIC objective. Fluorescence images were adjusted for brightness, contrast and colour balance by using the ImageJ software.

\section{Flow cytometry analysis of JC-1, MitoSox and Annexin 5/PI stained cells}

Dictyostelium cells were washed in incubation buffer $\left(2 \mathrm{mM} \mathrm{Na}_{2} \mathrm{HPO}_{4}, 15 \mathrm{mM} \mathrm{KH}_{2} \mathrm{PO}_{4}, 310 \mu \mathrm{M} \mathrm{CaCl}_{2}\right.$, $500 \mu \mathrm{M} \mathrm{MgCl}_{2}, 1.35 \mathrm{mM} \mathrm{KCl}, 1.8 \%$ Maltose, pH6). Cells (5x105) were incubated either in $5 \mu \mathrm{M} \mathrm{Mi-}$ toSox Red or $2 \mu \mathrm{M} \mathrm{JC}-1$ dye (ThermoFisher Scientific, Illkirsh, France) for $30 \mathrm{~min}$ at $22^{\circ} \mathrm{C}$ with shaking, and then washed twice before FACS analysis. As positive control of JC-1 staining, $5 \mu \mathrm{M}$ carbonyl cyanide m-chlorophenyl hydrazone (CCCP) was added to cells during JC-1 cell incubation. For MitoSox red staining of HeLa cells, $2.5 \times 10^{5}$ cells resuspended in CPBS buffer (PBS, $2.67 \mathrm{mM}$ $\mathrm{KCl}, 0.5 \mathrm{mM} \mathrm{MgCl}_{2}, 0.7 \mathrm{mM} \mathrm{CaCl}$ and $0.1 \%$ glucose) were incubated in $5 \mu \mathrm{M}$ MitoSox red. After $20 \mathrm{~min}$ at $37^{\circ} \mathrm{C}$ with shaking, cells were washed twice in CPBS buffer before FACS analysis. JC-1 staining of HeLa cells was made according to the manufacturer recommendations. Briefly, cells cultured in 6-well culture plates $\left(2.5 \times 10^{5} /\right.$ well $)$ were incubated at $37^{\circ} \mathrm{C}$ in culture medium supplemented with $2 \mu \mathrm{M}$ JC1. After 30min, cells were washed, resuspended in PBS, and directly analysed by flow cytometry. To detect cell death upon oxidative stress, $2.5 \times 10^{5} \mathrm{Hela}$ cells were resuspended in $50 \mu \mathrm{L}$ Annexin $\mathrm{V}$ buffer (10 mM HEPES pH7, 140mM NaCl, $2.5 \mathrm{mM} \mathrm{CaCl}_{2}$ ) and incubated at room 
temperature with $5 \mu \mathrm{L}$ Annexin V-FITC (eBioscience, Vienna, Austria) and $10 \mu \mathrm{L}$ propidium iodide (stock $0.1 \mathrm{mg} / \mathrm{mL}$ ). After $15 \mathrm{~min}$, cells were washed once in PBS before FACS analysis.

\section{MACS enrichment of CD4-Rv1813c transfected cells}

MACS enrichment of transfected cells was done with MACSelect Transfected Cell Selection kit from Miltenyi Biotec, according to the supplier. Briefly, HeLa cells were transfected with empty PMACS4-IRESII or pMACS4-IRESII-Rv1813c plasmids allowing expression of truncated CD4 cell surface marker alone or in combination with $\mathrm{Rv} 1813 \mathrm{c}$ respectively. After $24 \mathrm{~h}, \sim 10^{7}$ cells were washed, dissociated in ice cold PBS containing $5 \mathrm{mM}$ EDTA, centrifuged at $200 \mathrm{~g}$ for 10 minutes at $4^{\circ} \mathrm{C}$, and resuspended in $320 \mu$ ice-cold de-gassed PBS supplemented with $0.5 \%$ bovine serum albumin and $5 \mathrm{mM}$ EDTA (PBE). Magnetic labelling of the transfected cells was achieved by incubating cells with $80 \mu \mathrm{l}$ of anti-CD4 coupled MACSelect MicroBeads on ice for 15 minutes. Volume was adjusted to $2 \mathrm{ml}$ with PBE and cells were subjected to magnetic separation using LS column (Miltenyi Biotec) and MACS separator. After three washes with $3 \mathrm{ml}$ of PBE, cells were flushed out with $5 \mathrm{ml}$ of PBE. To increase the purity of the magnetically labelled fraction, magnetic separation was repeated once on a second LS column. After the final wash, cells were flushed out with $5 \mathrm{ml}$ of cell culture medium, counted and seeded at a density of $1.85 \times 10^{4}$ cells/well on XF96 cell culture microplates (Seahorse, Agilent Technologies, France) previously coated with $0.1 \mathrm{mg} / \mathrm{ml}$ poly-D-Lysine (\#P7280, SIGMA) or on glass coverslips to evaluate the level of MACS enrichment of transfected cells by immunofluorescence. Cells were incubated at $37^{\circ} \mathrm{C}$ and analysed $24 \mathrm{~h}$ later using the Seahorse XF96 extracellular flux analyser or by confocal microscopy.

\section{Extracellular flux analysis}

Cells plated the day before on XF96 cell culture microplates were washed with pre-warmed cell culture medium $5 \mathrm{~h}$ before analysis to eliminate dead cells. Extracellular Flux analysis was performed using Seahorse XF Extracellular Flux analyser, allowing simultaneous measurement of oxygen consumption rate (OCR) and extracellular acidification rate (ECAR). Mitochondrial respiration and glycolytic function of the cells were measured using Cell Mito Stress Test Kit (\#103015-100) and Cell Glycolysis Stress Test Kit (\#103020-100), respectively (Agilent Technologies, France). Cells were incubated in Seahorse XF DMEM pH7.4 (\#103575-100, Agilent) supplemented with 1 mM sodium pyruvate, $2 \mathrm{mM}$ glutamine and with $10 \mathrm{mM}$ glucose (Cell Mito Stress Test Kit) or without glucose (Cell Glycolysis Stress Test Kit) in a $37^{\circ} \mathrm{C}$ incubator without $\mathrm{CO}_{2}$ for $1 \mathrm{~h}$ prior to the assay. After calibration and three initial measurements at baseline, different perturbing chemicals corresponding to each kit were sequentially injected, and three successive measurements were taken after each injection. 
MACS enriched cells on glass coverslips were successively fixed with $2.5 \%$ gluteraldehyde in 0.1 $\mathrm{M}$ cacodylate buffer $\mathrm{pH} 7.4$, washed with cacodylate buffer, post-fixed in $1 \%$ osmium tetroxide in cacodylate buffer, washed with distilled water, and finally incubated in $1 \%$ uranyl acetate. Dehydration was performed through acetonitrile series. Samples were impregnated first in epon 118: acetonitrile 50:50, and twice in $100 \%$ epon. After overnight polymerization at $60^{\circ} \mathrm{C}$, coverslips were detached by thermal shock with liquid nitrogen. Polymerization was then prolonged for $48 \mathrm{~h}$ at $60^{\circ} \mathrm{C}$. Ultrathin sections of $70 \mathrm{~nm}$ were cut with a Leica UC7 ultramicrotome (Leica microsystems), counterstained with lead citrate and uranyl acetate prepared in ethanol. Sections were observed in a Jeol 1200 EXII transmission electron microscope. All chemicals were from Electron Microscopy Sciences (USA) and solvents were from Sigma. Images were processed using the Fiji software. 
A

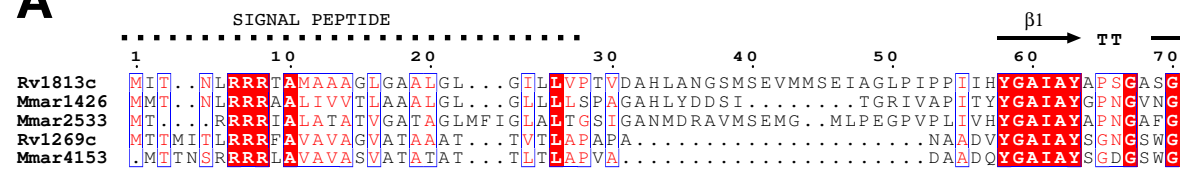

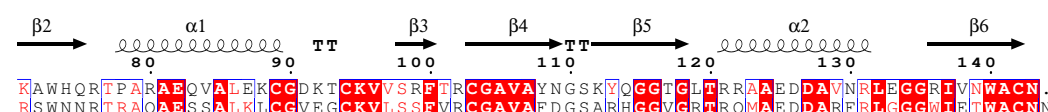

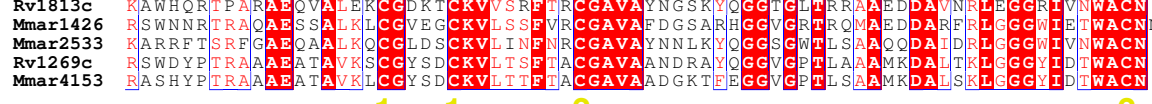
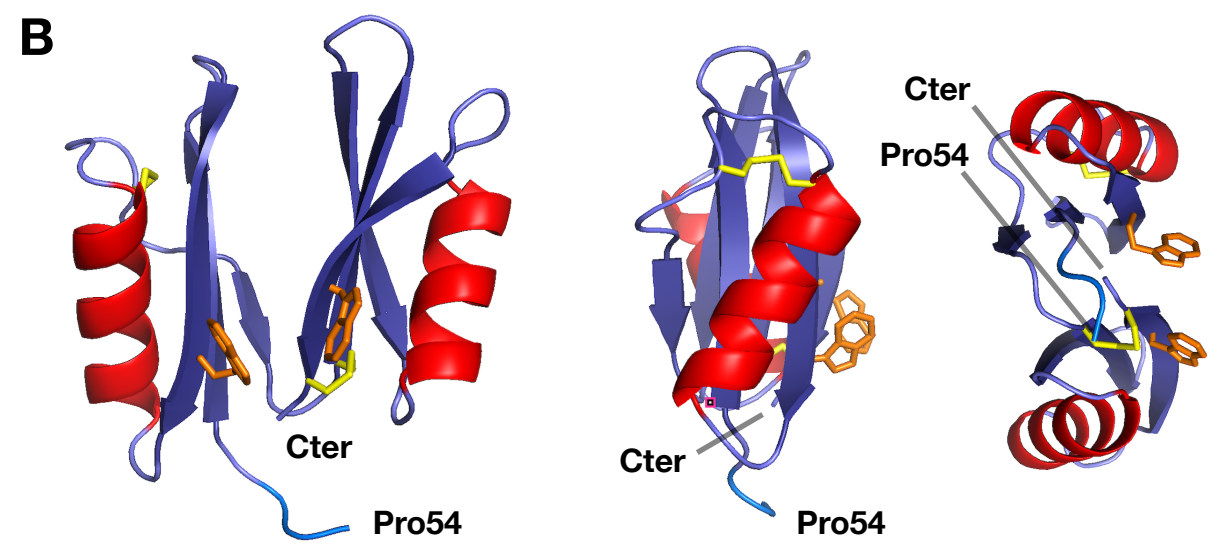


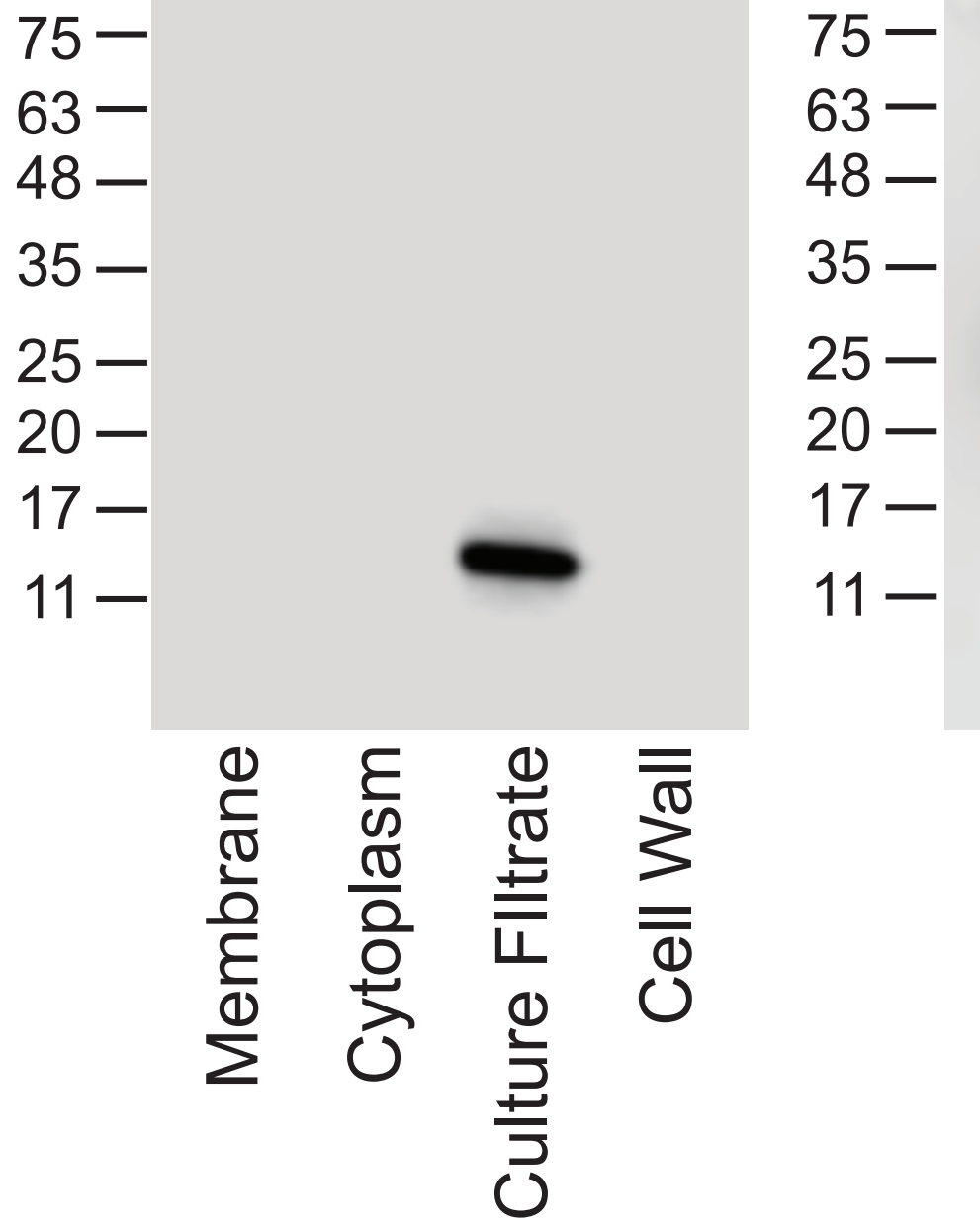

Anti-FtsZ

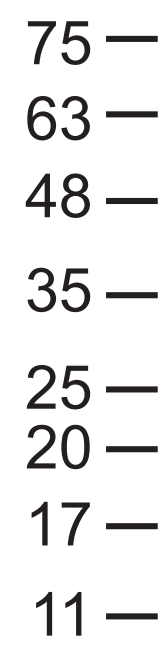

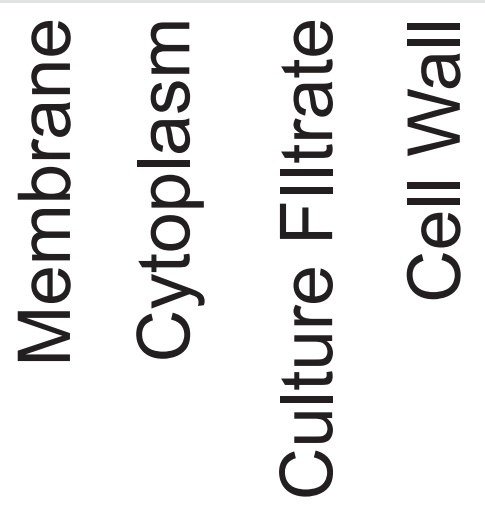

Anti-GInA

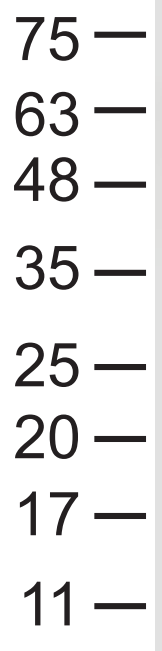


Figure 3

A

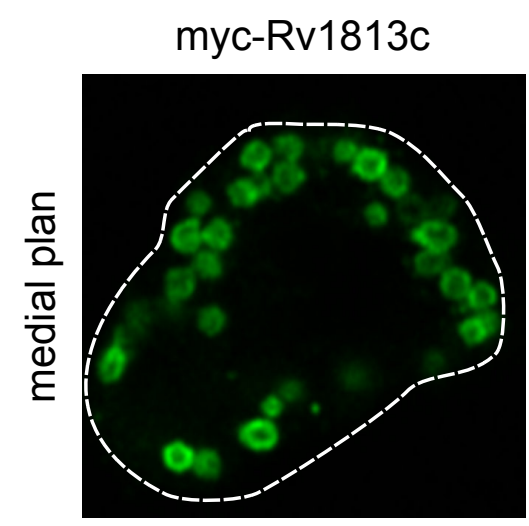

Mitoporin

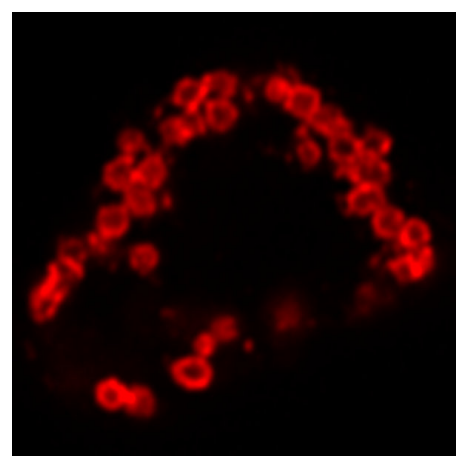

B
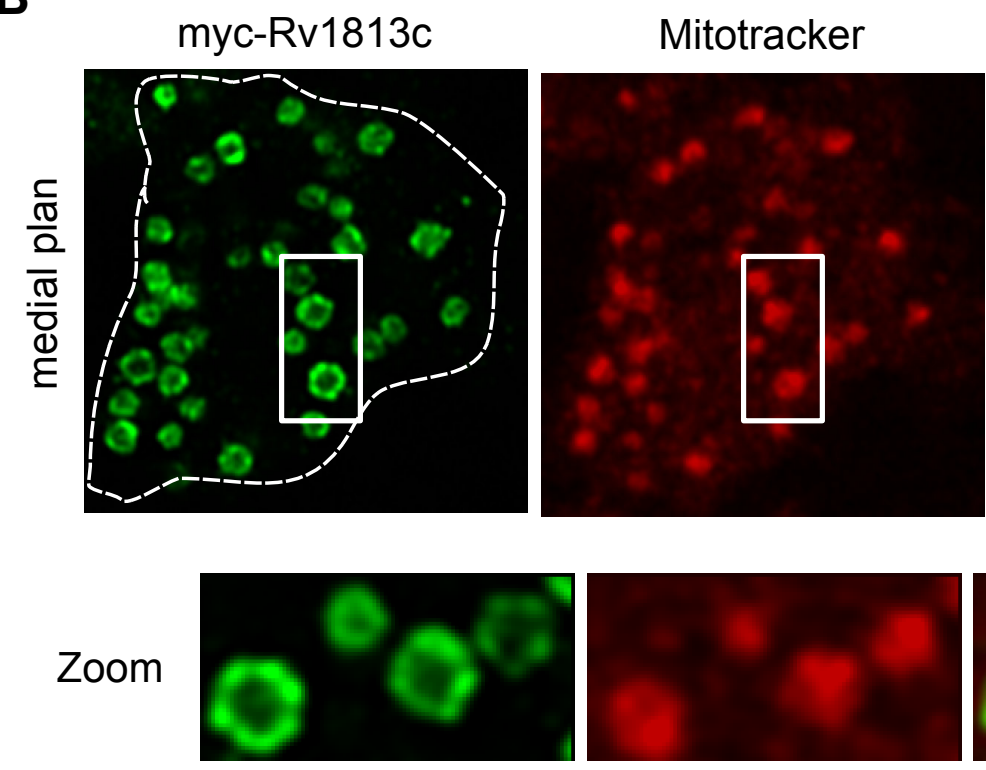

C

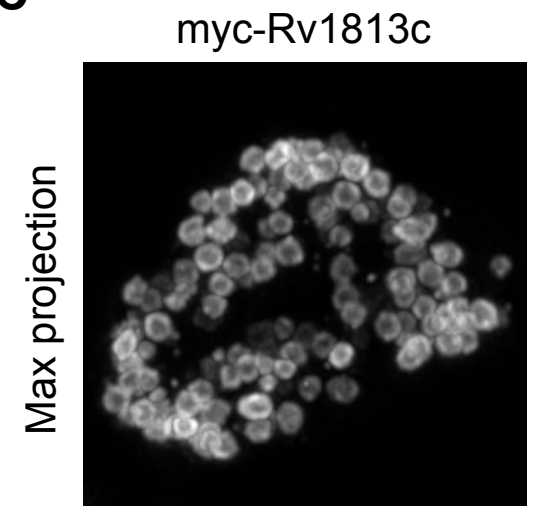

$m y c-R v 1813 c-49-143$

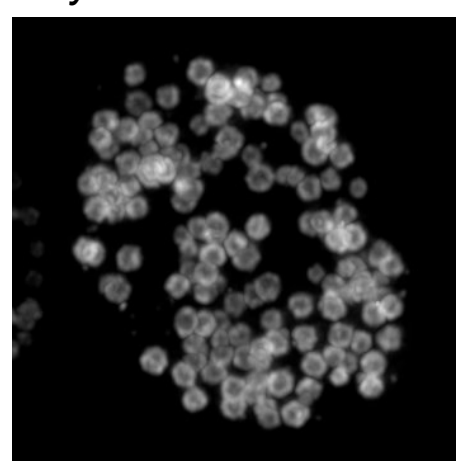

merge

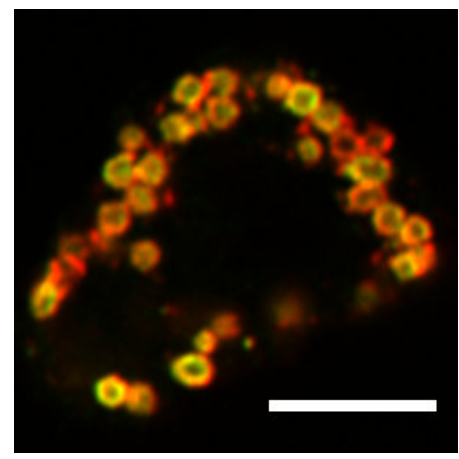

merge
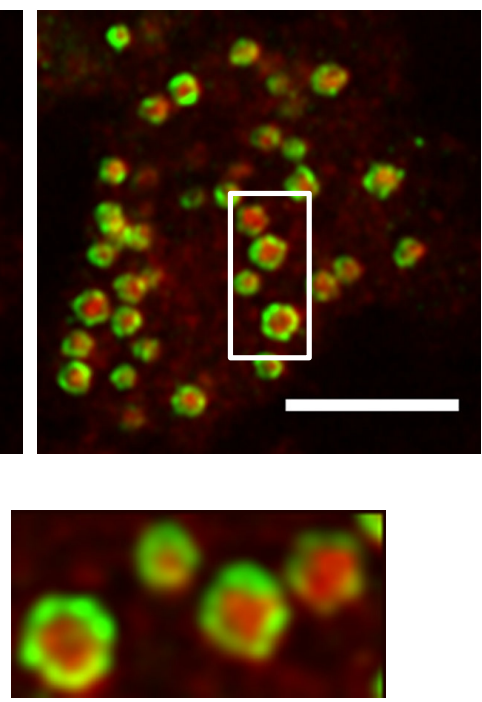

myc-Rv1813c-28-56

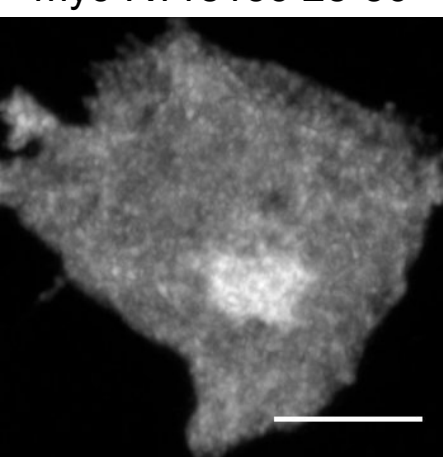


Figure 4

A

cell disruption<smiles>CC([SeH])[SeH]</smiles>

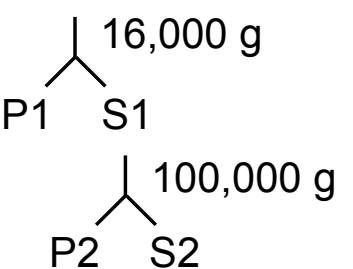

B

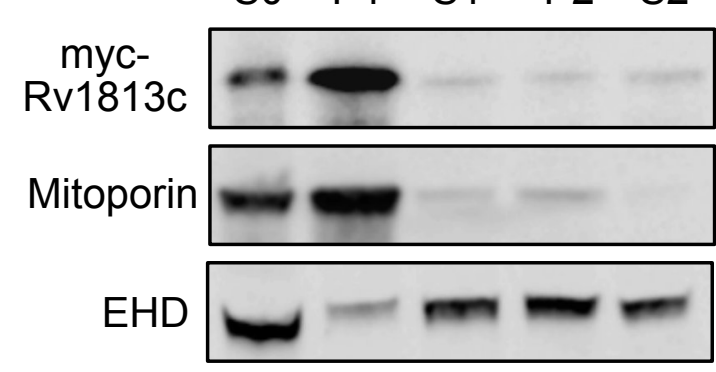

C

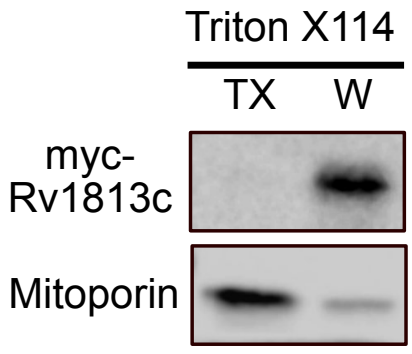

D

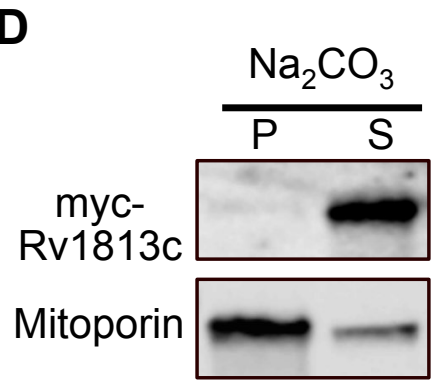

E

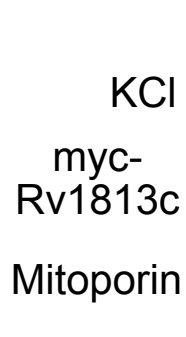

F

G

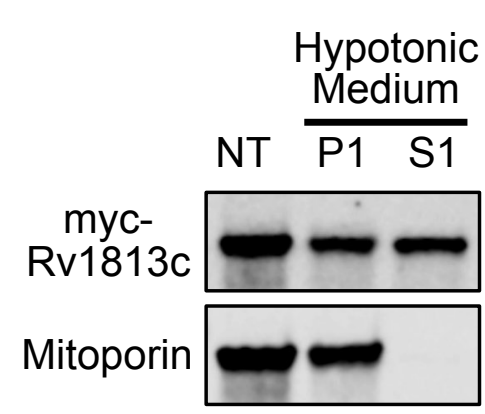

H

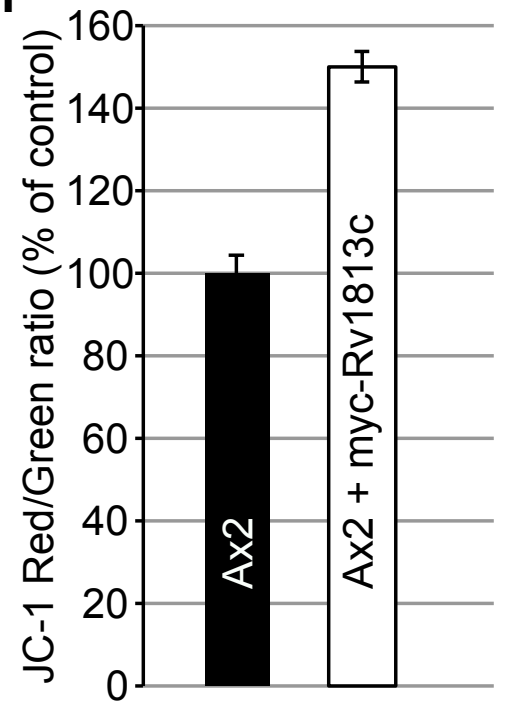

I

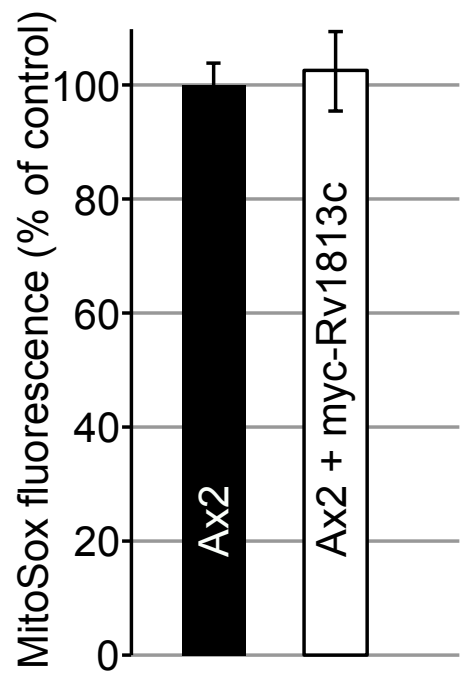

J

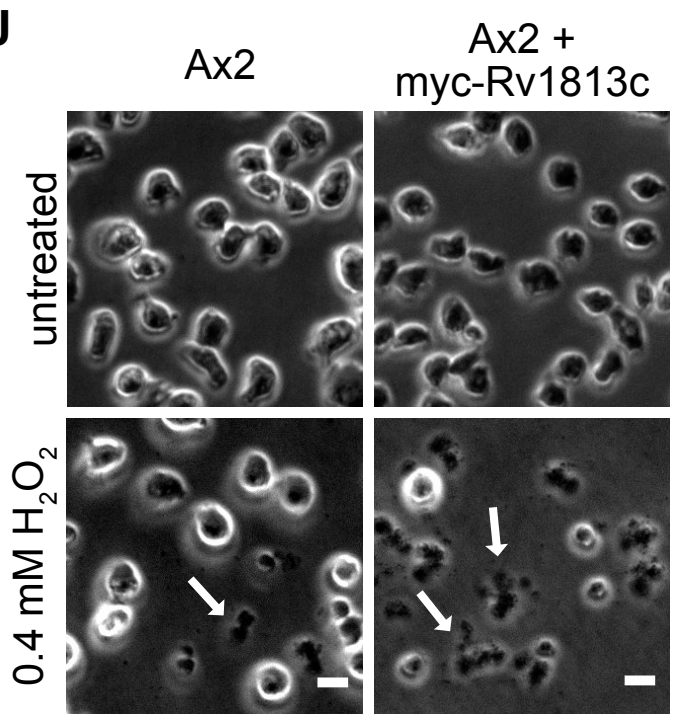

K

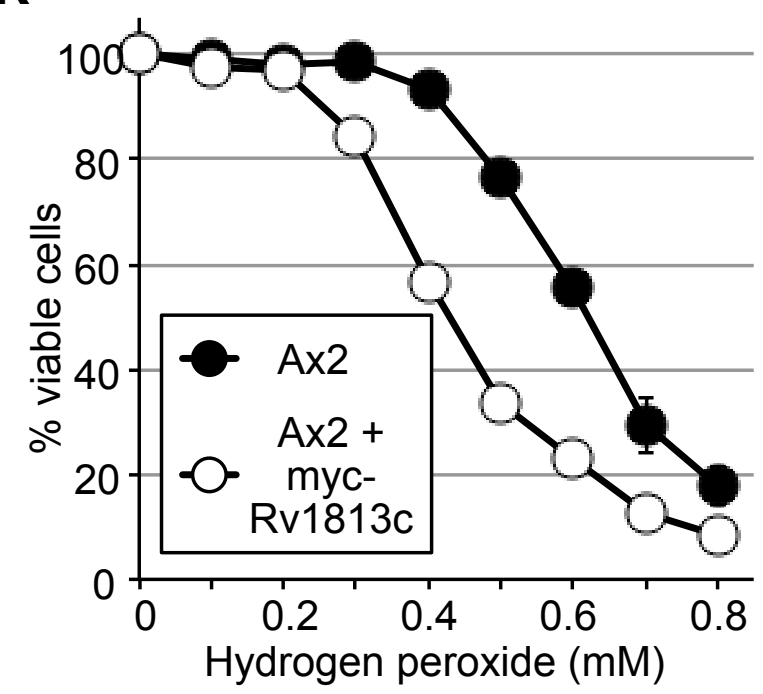


Figure 5

A

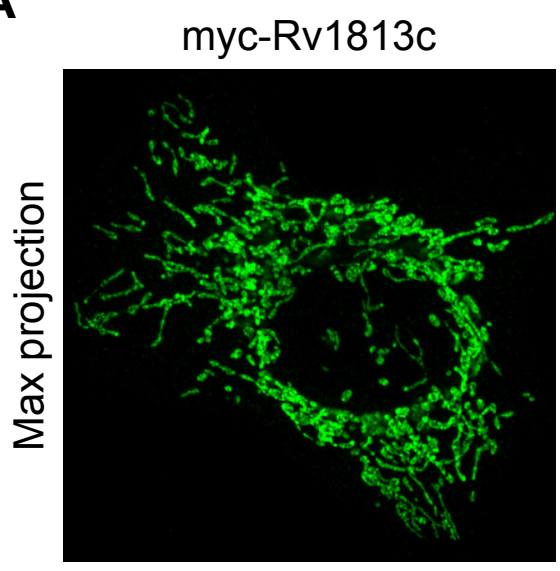

Cytochrome c

merge

B
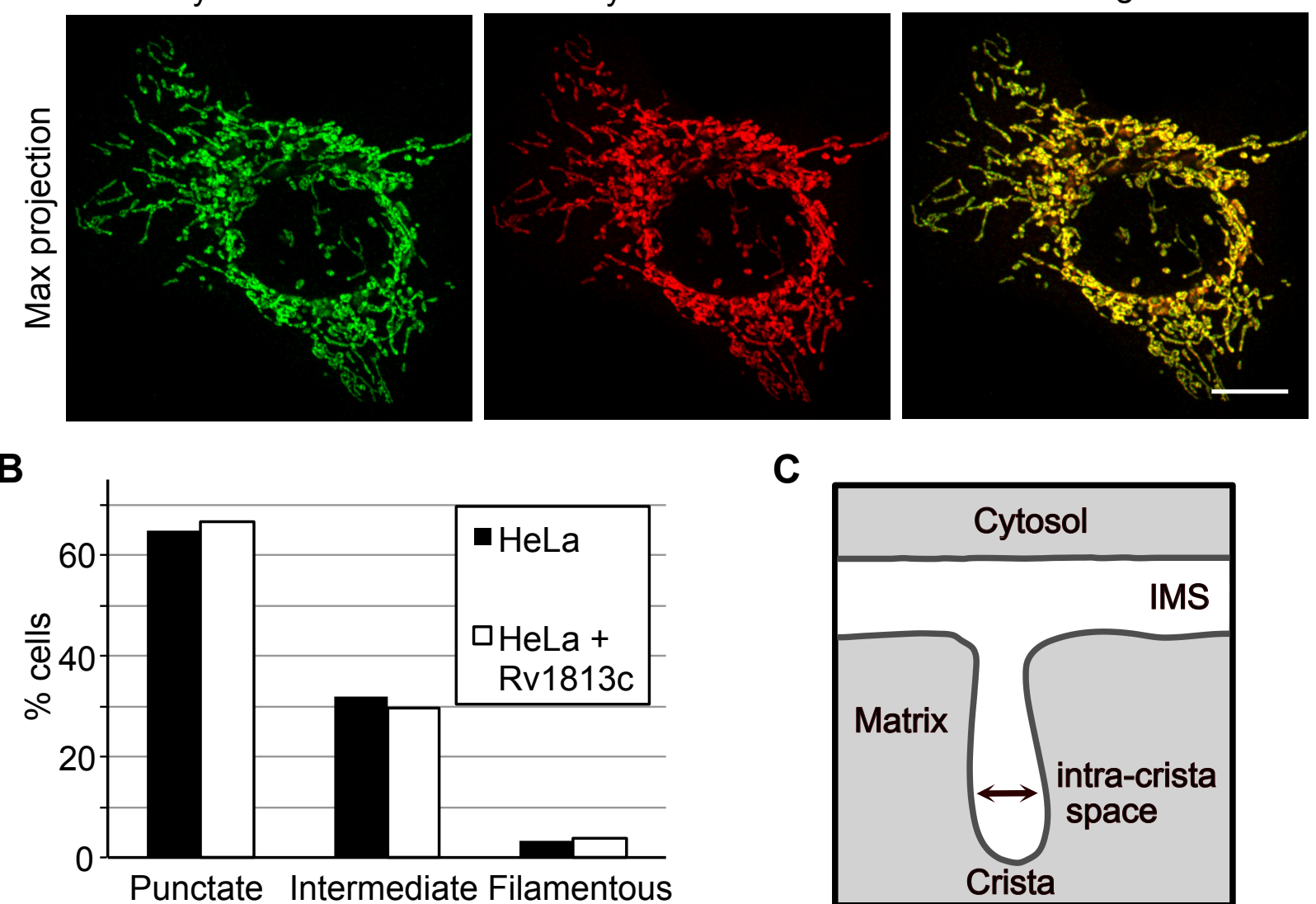

C

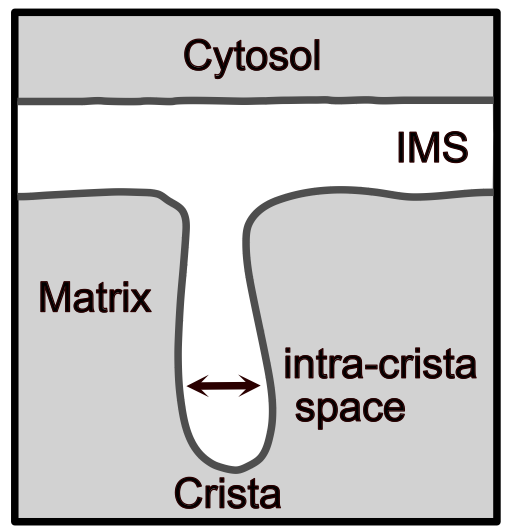

D
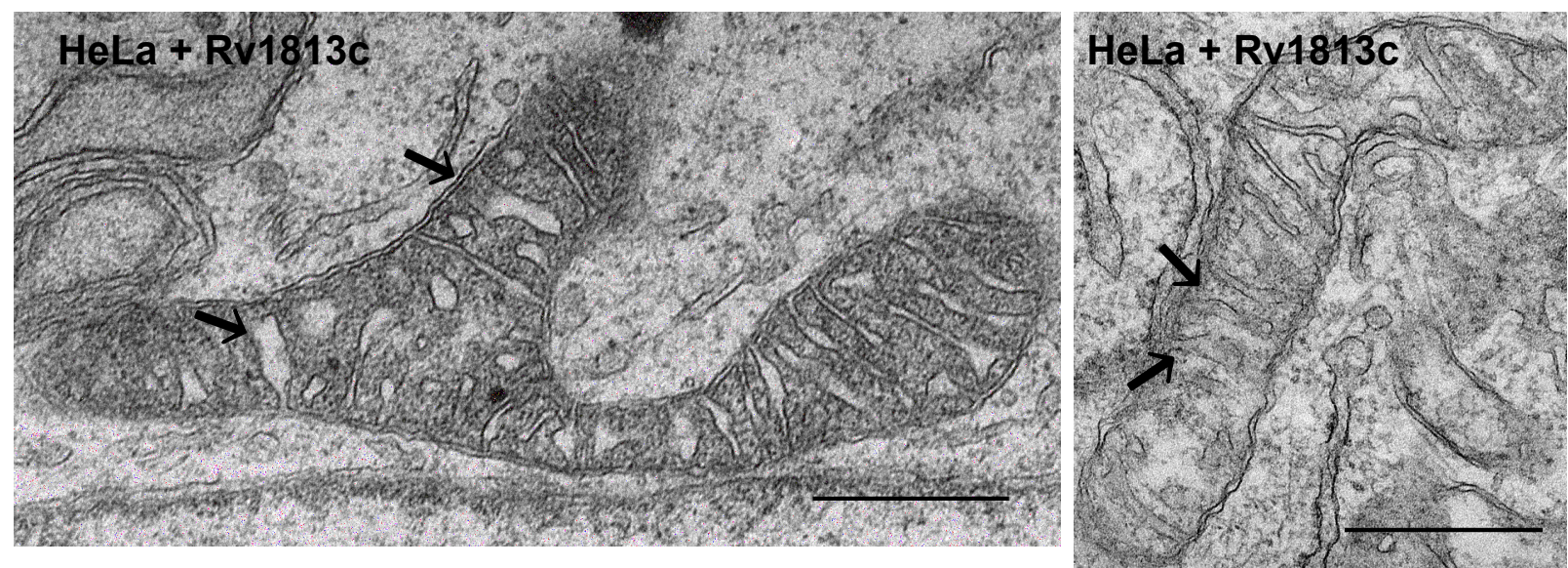

E

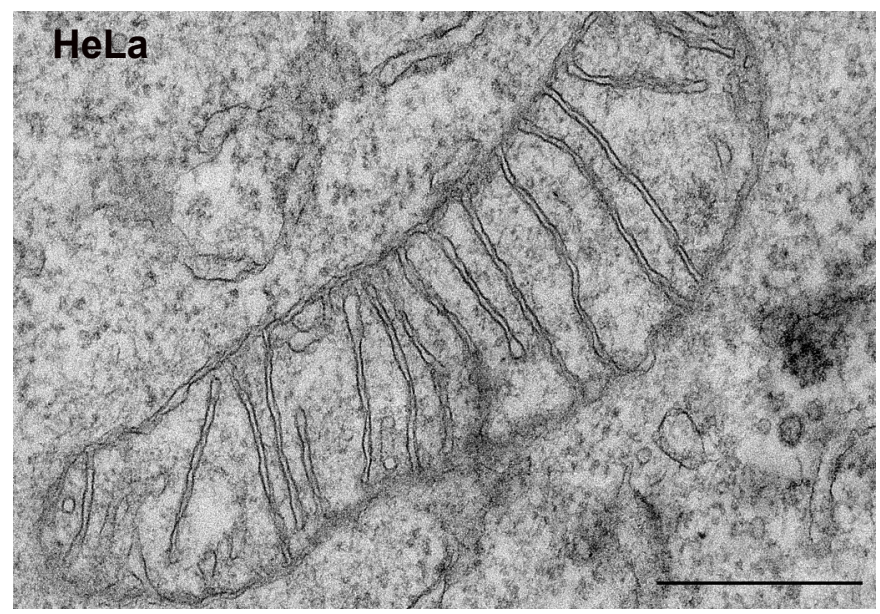

F

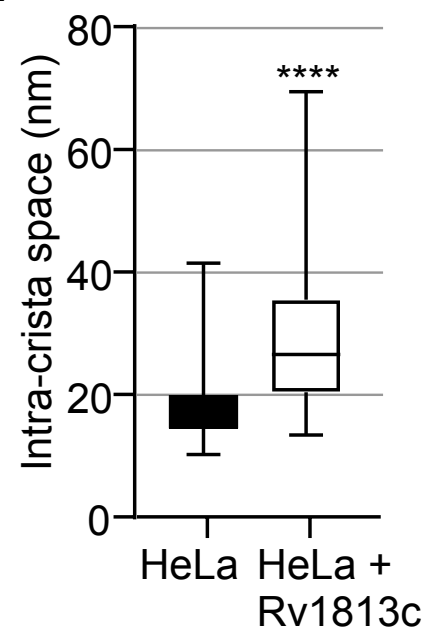


A

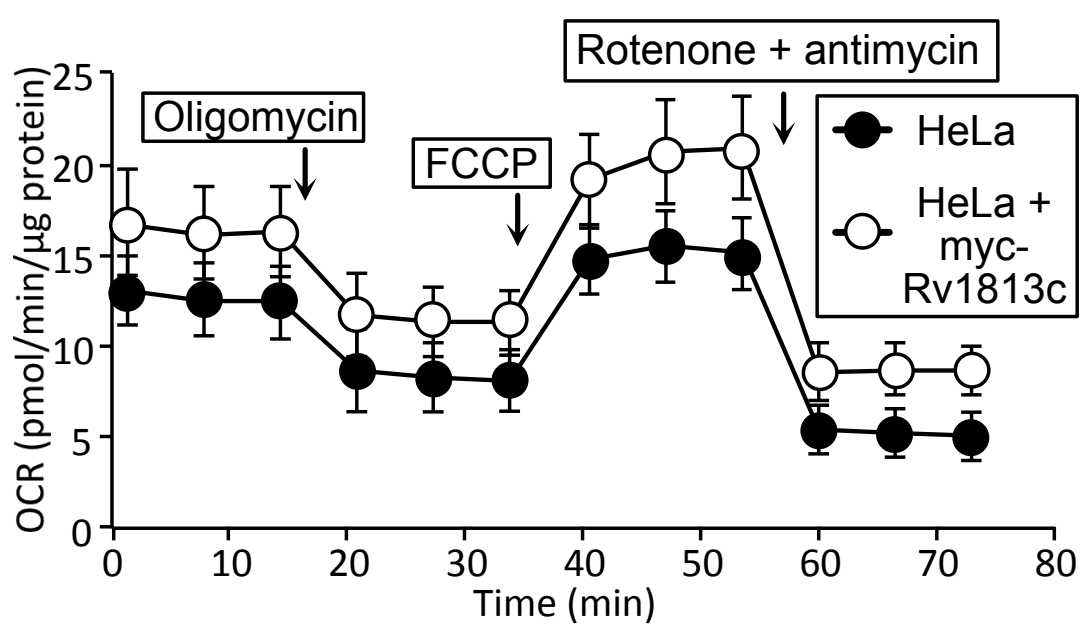

B

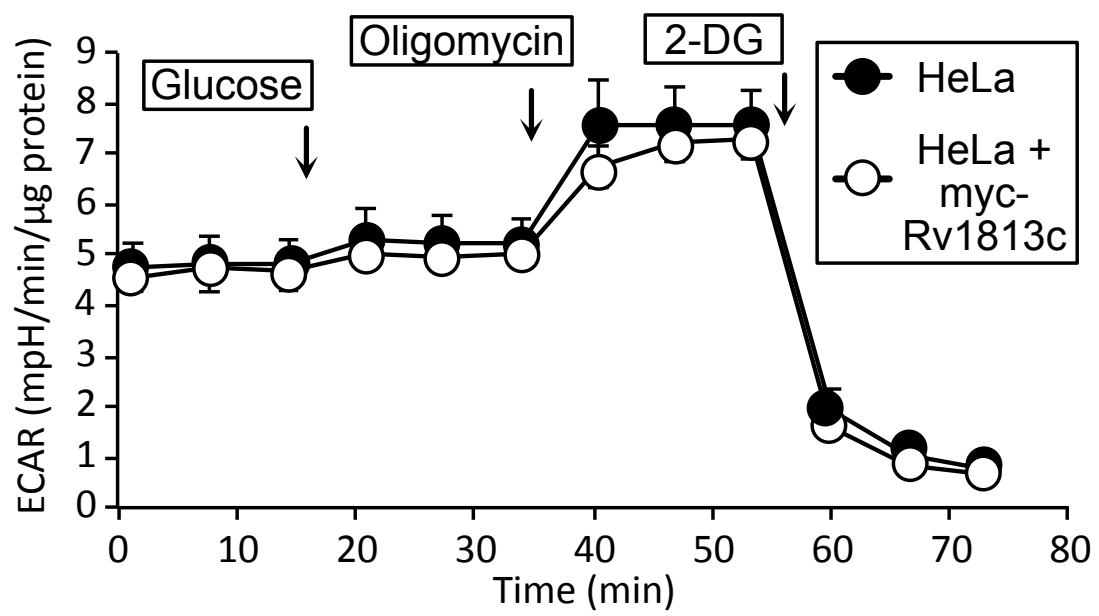

C

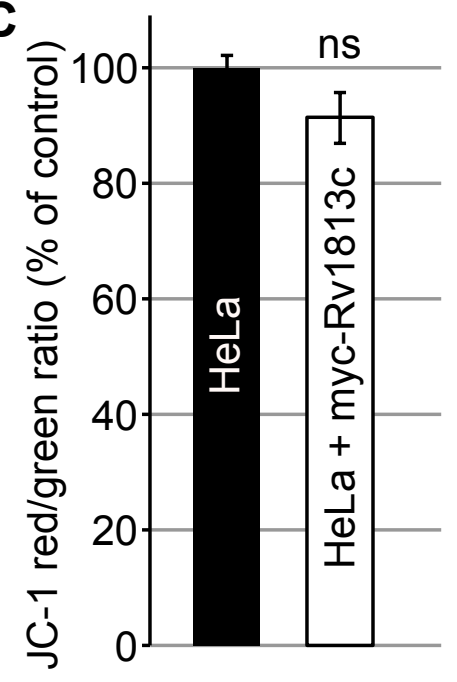

D

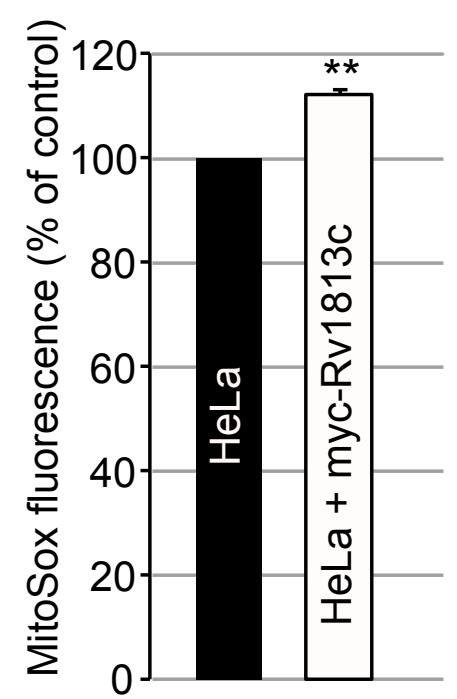

E

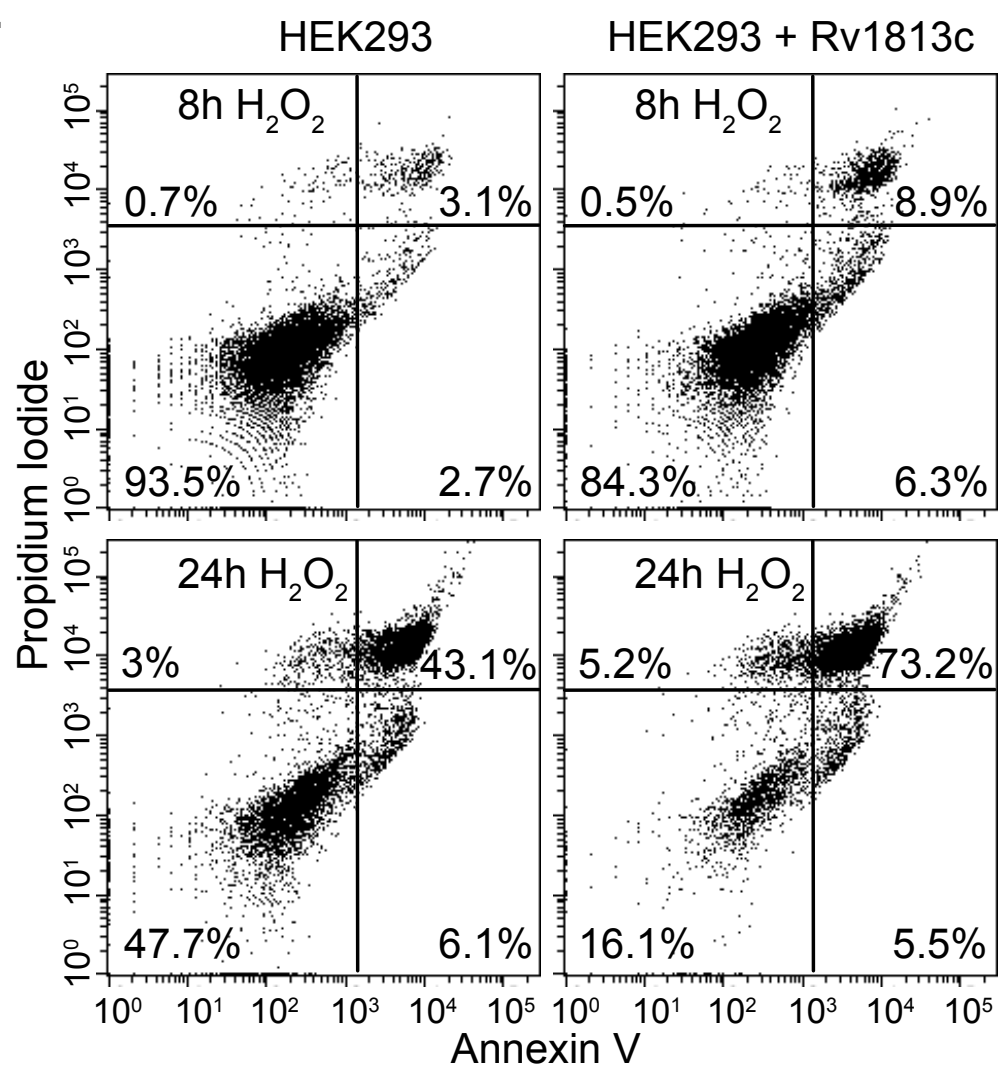

F

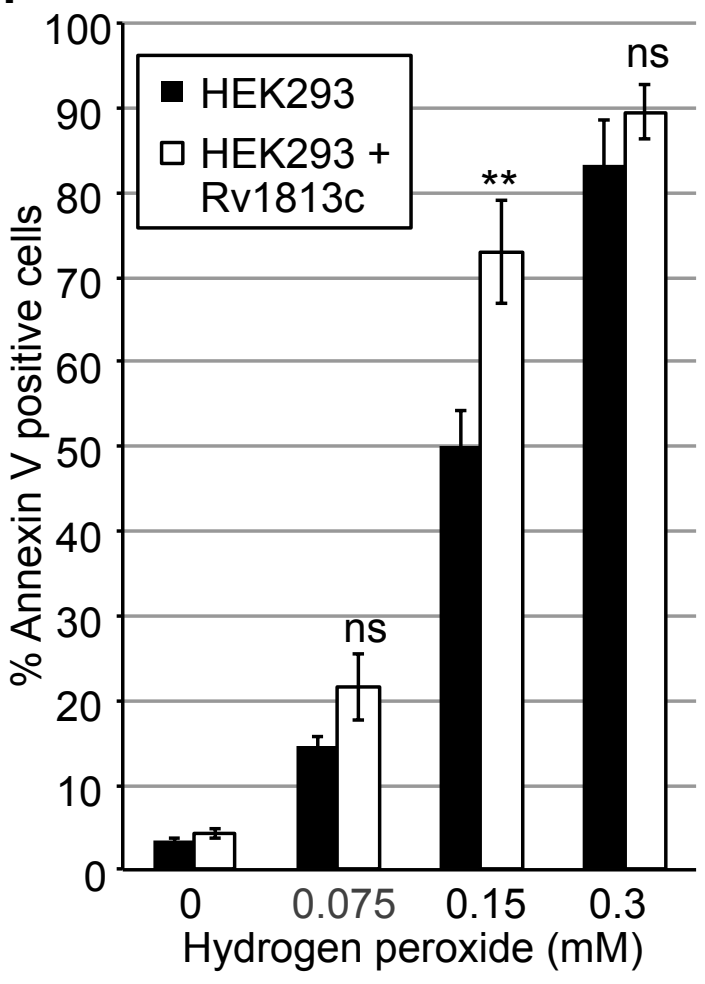


Figure 7

A

HeLa
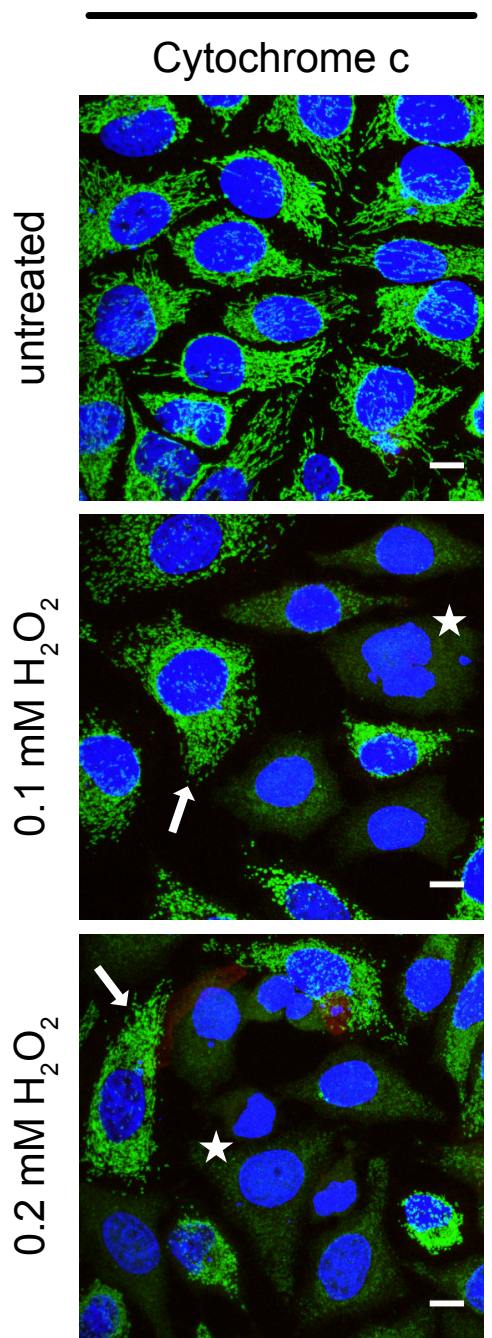

B

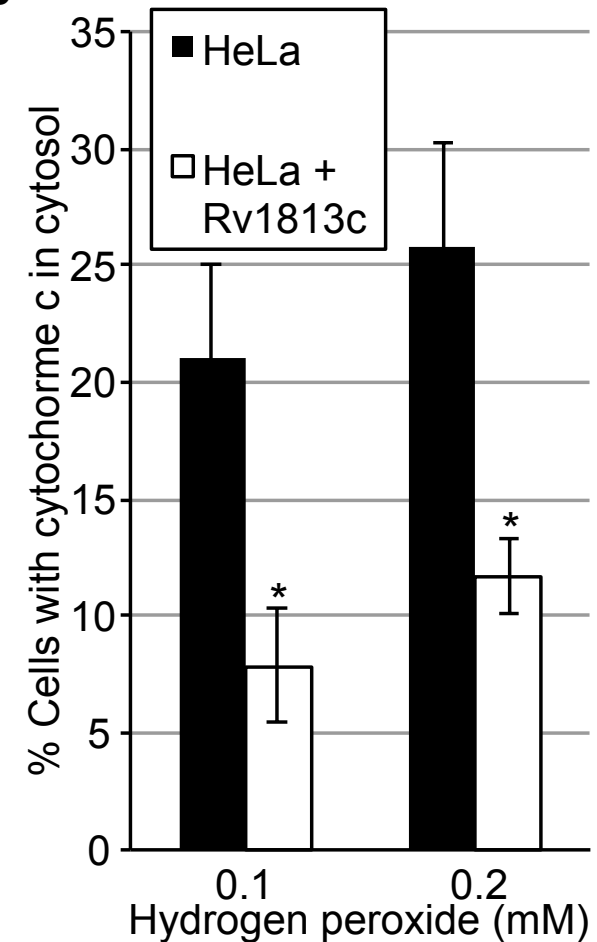

HeLa + Rv1813c
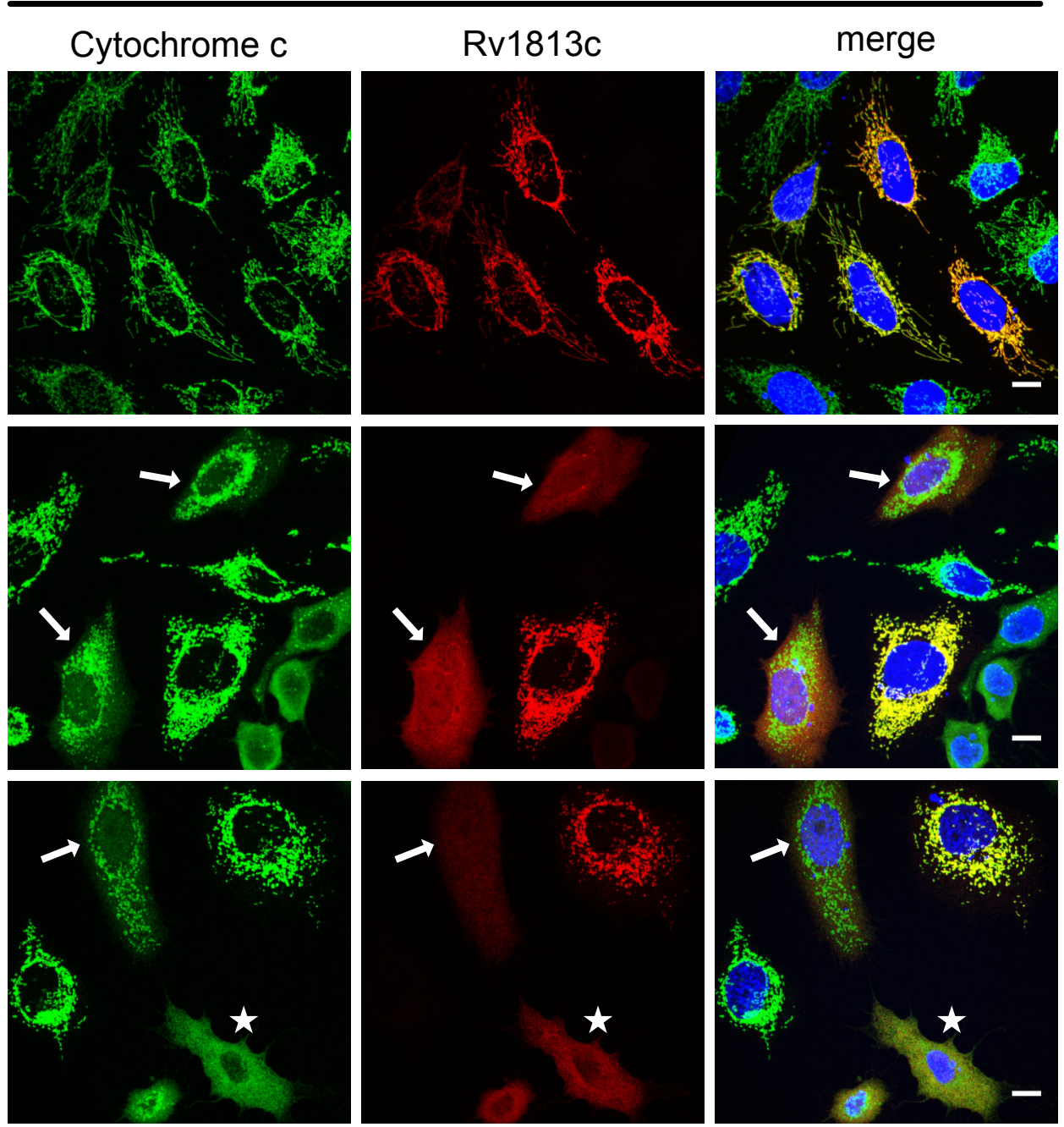

C

D

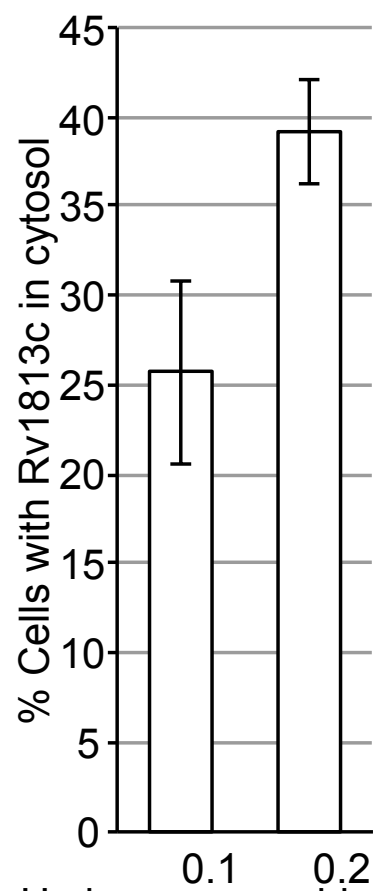

Hydrogen peroxide (mM)

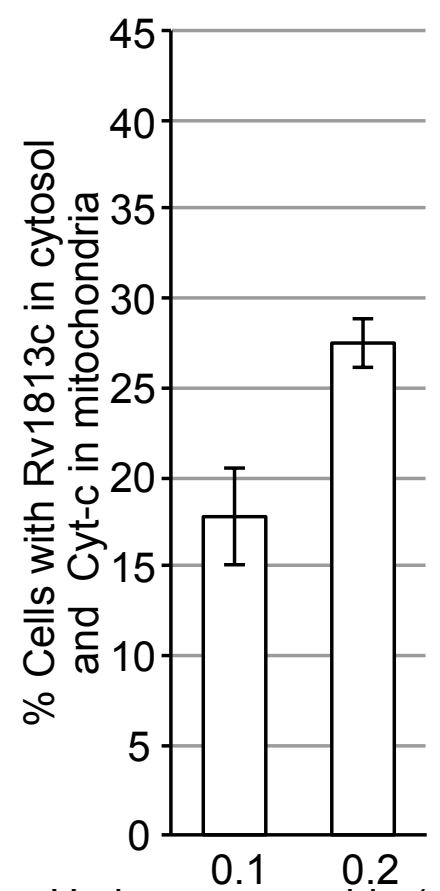

Hydrogen peroxide (mM) 


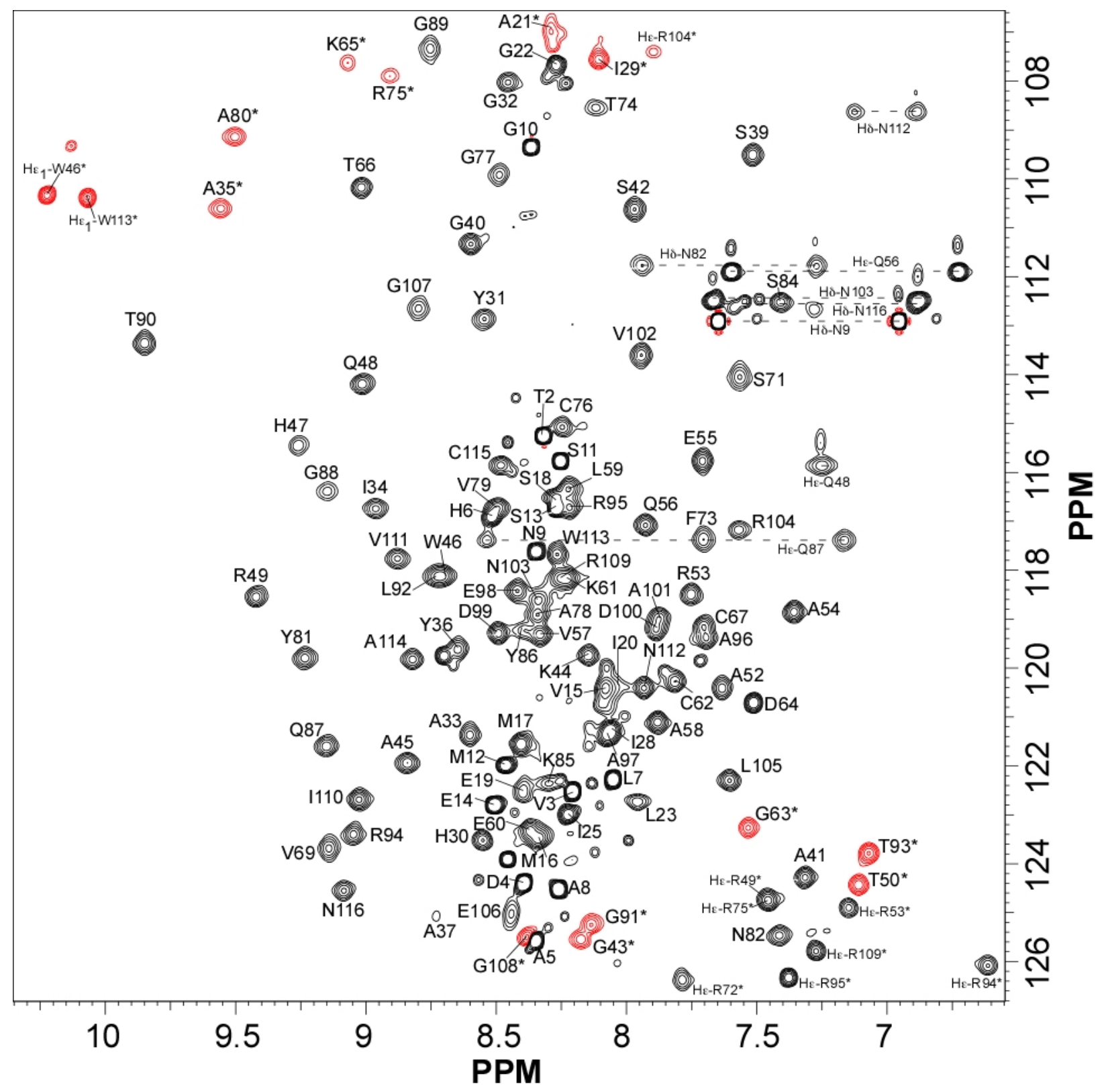


A Rv1813c pAb anti-Rv1813c

Mitoporin

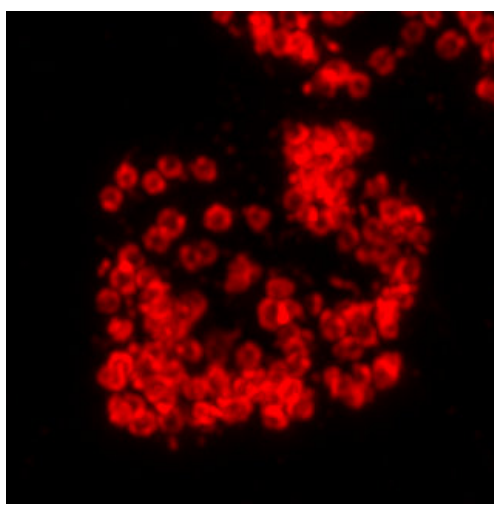

B
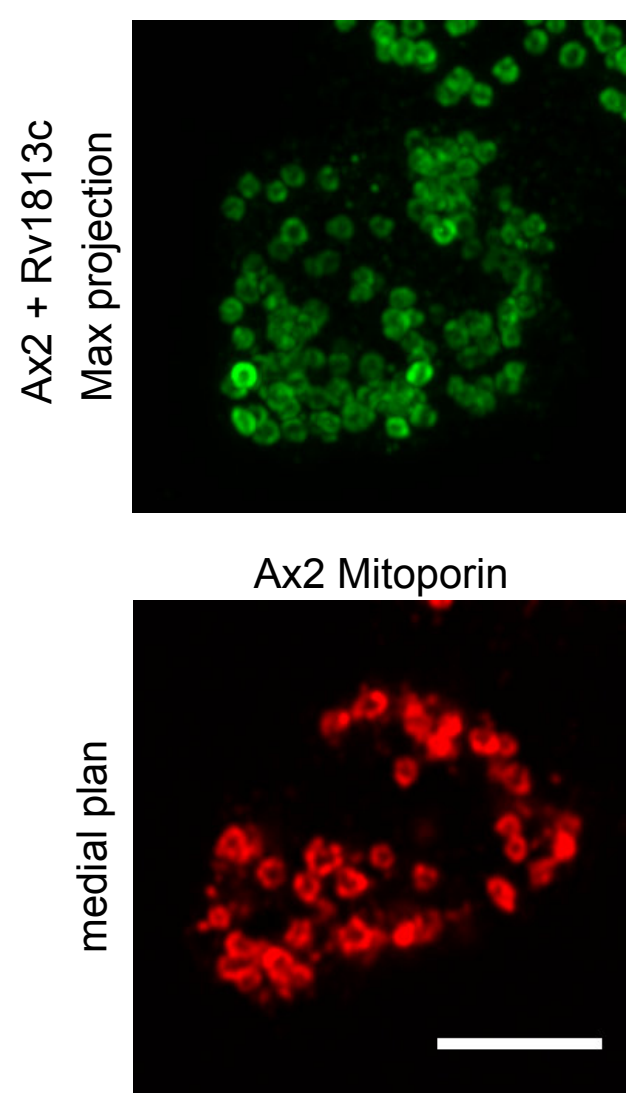

C

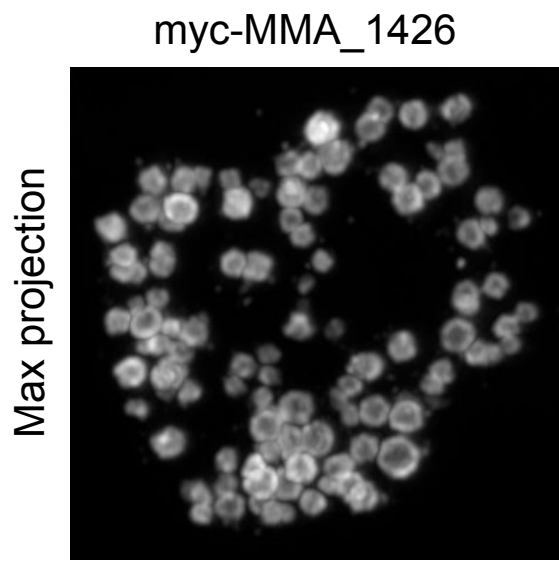

myc-Rv1269c
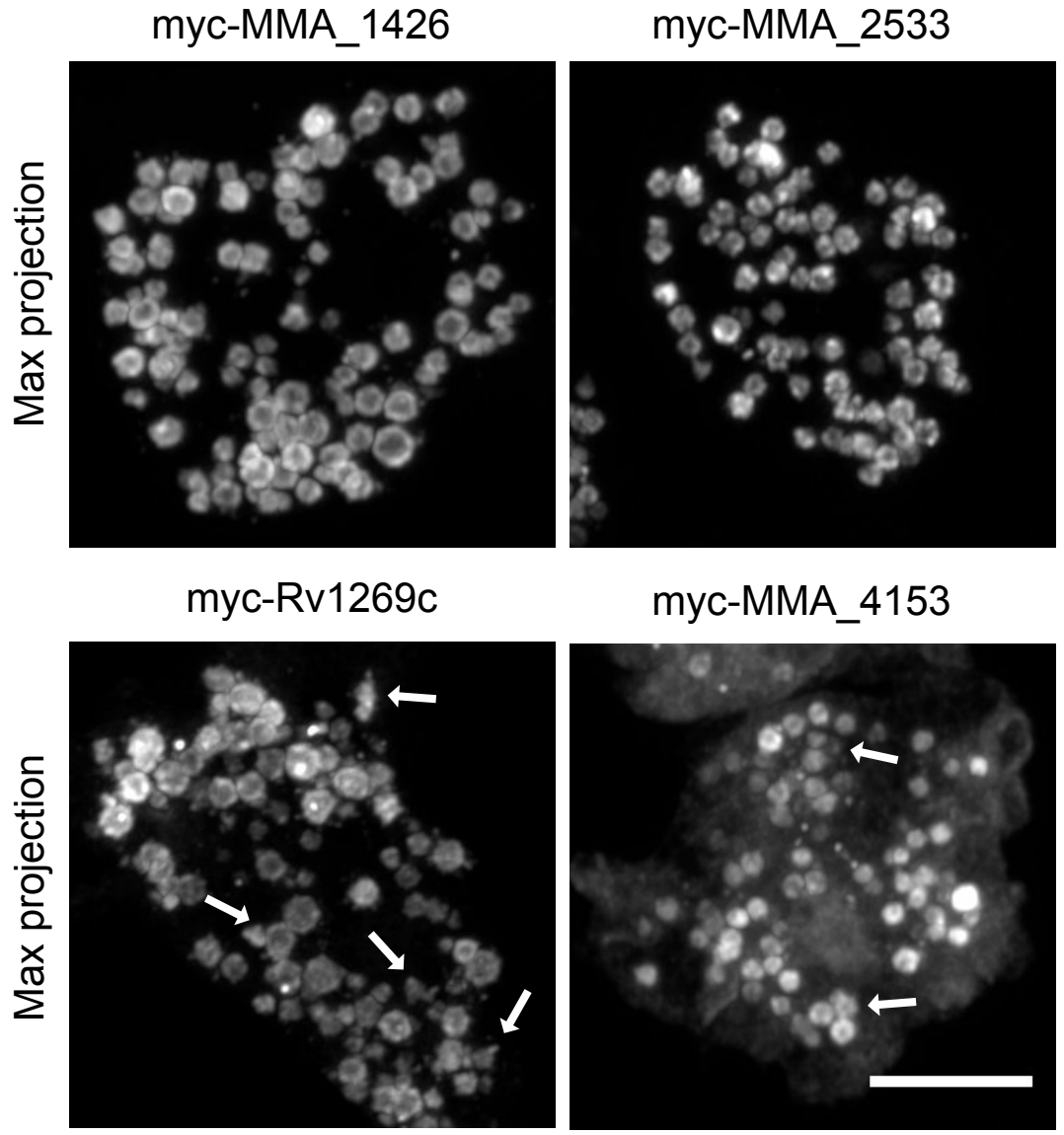

myc-MMA_4153

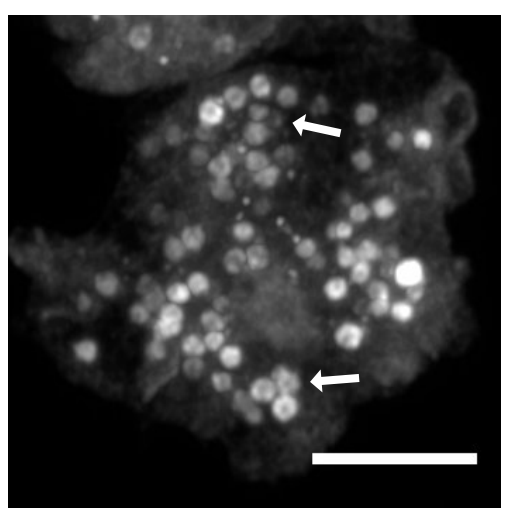

Ax2 Mitoporin

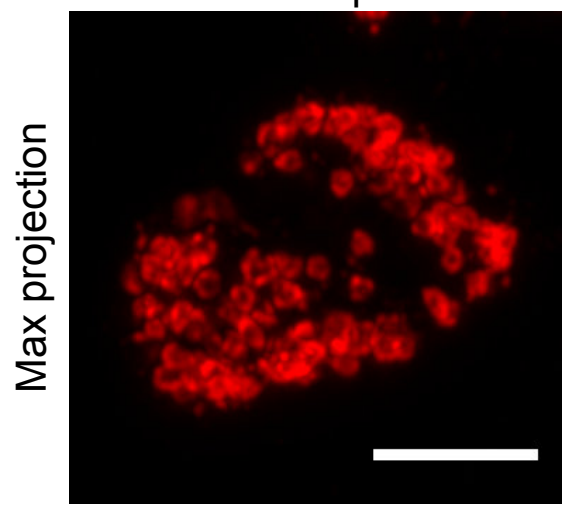

merge

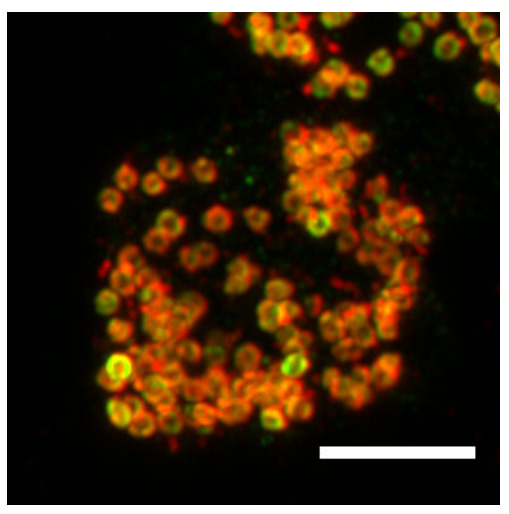


ES R Rxiv preprint doi: https://doi.org/10.1101/2021.01.31.428746; this version posted February 1, 2021. The copyright holder for this
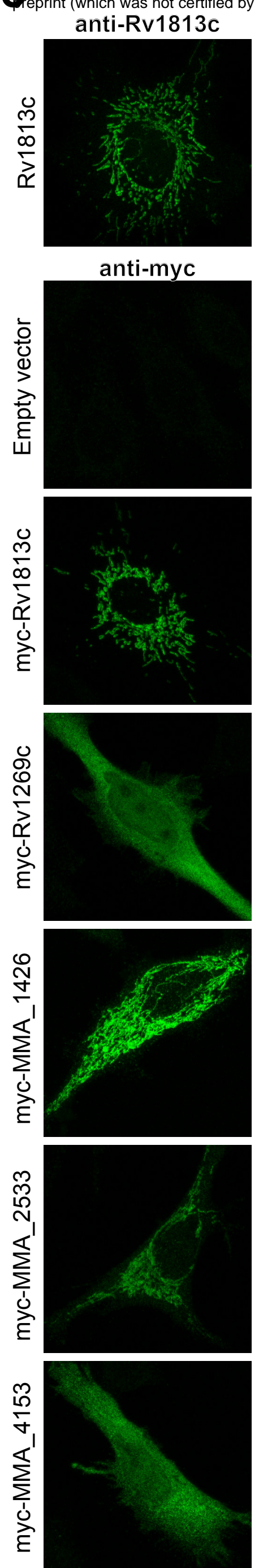

anti-cytochrome c

mitotracker

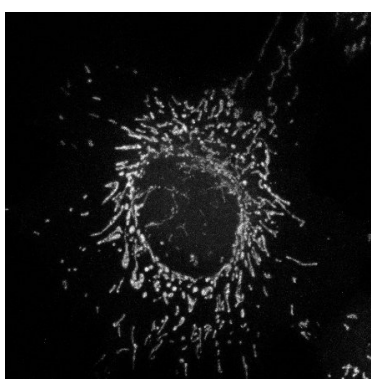

anti-grp75

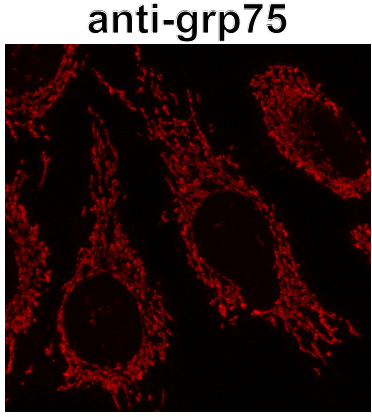

mitotracker
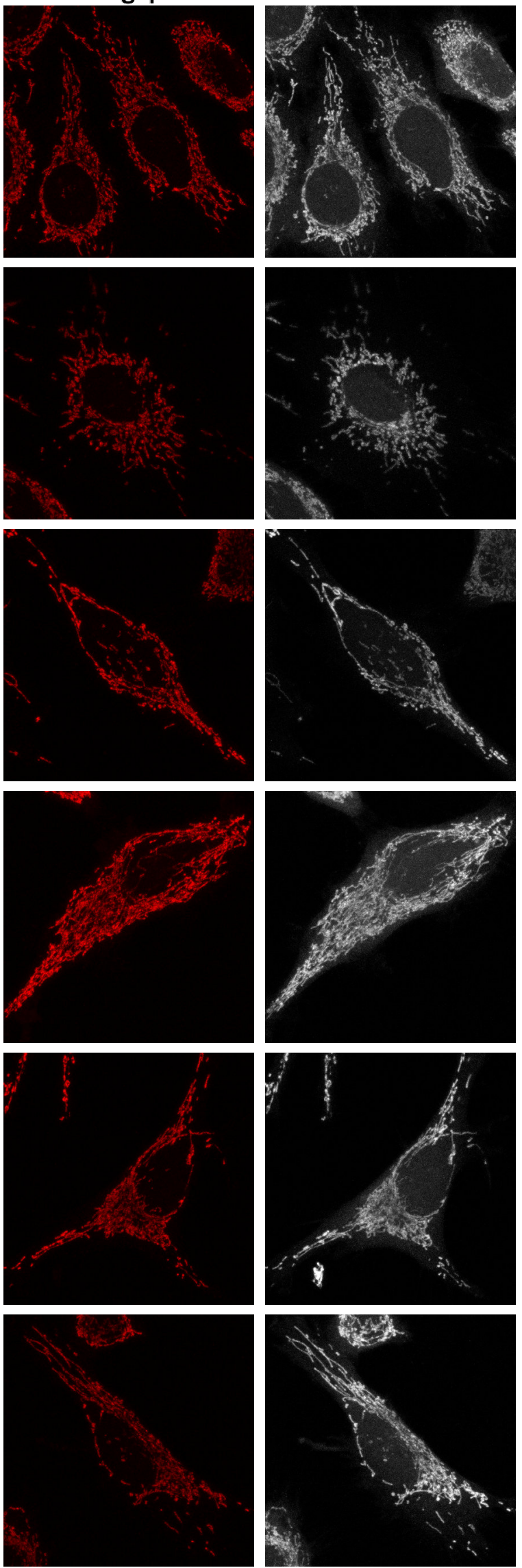
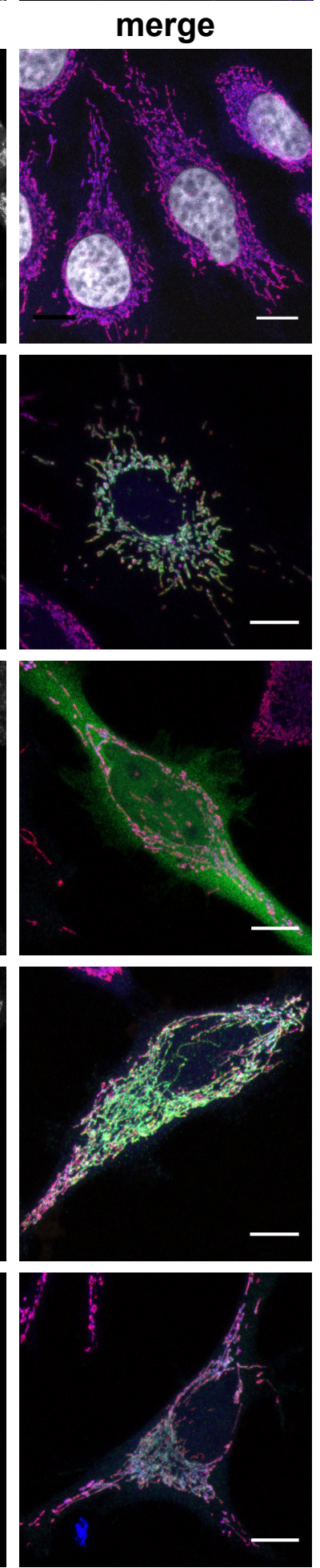

merge

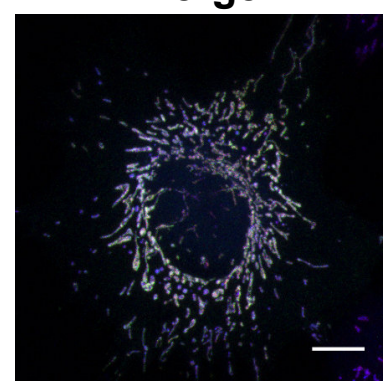

merge

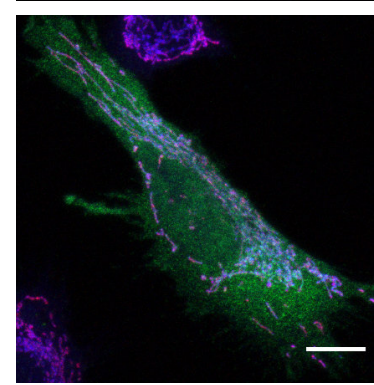


E 2 \&xiv preprint doi: https://doi.org/10.1101/2021.01.31.428746; this version posted February 1, 2021. The copyright holder for this Fifeprint (which was not certified by peer review) is the author/funder. All rights reserved. No reuse allowed without permission.
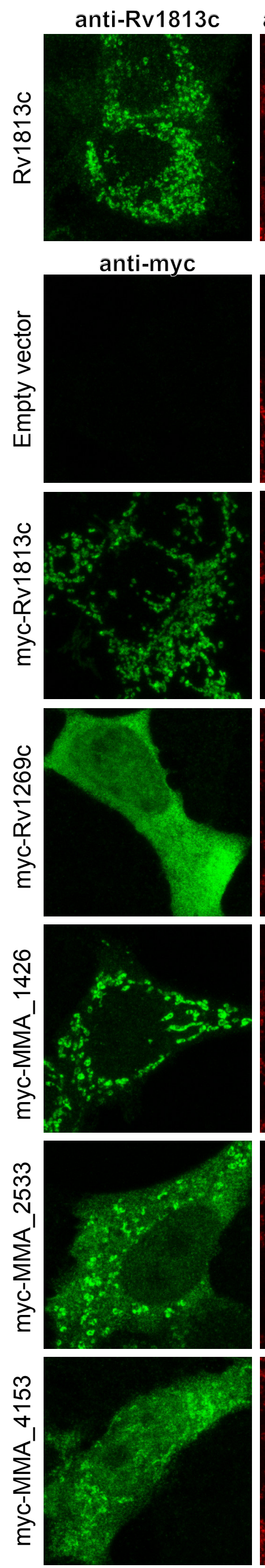

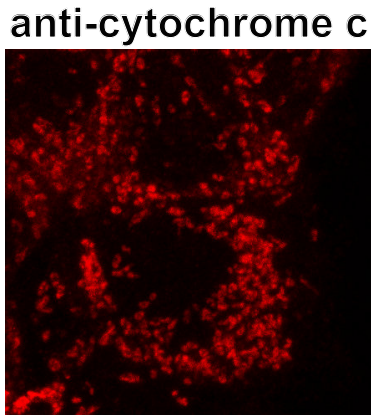

anti-grp75
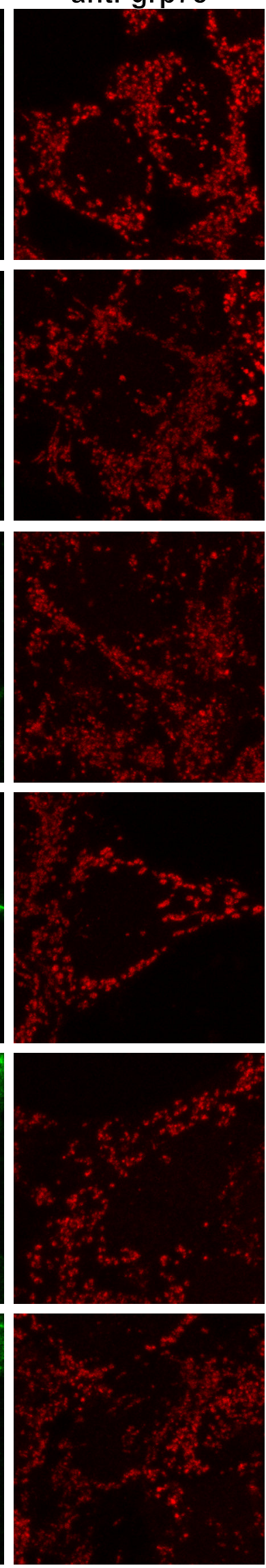
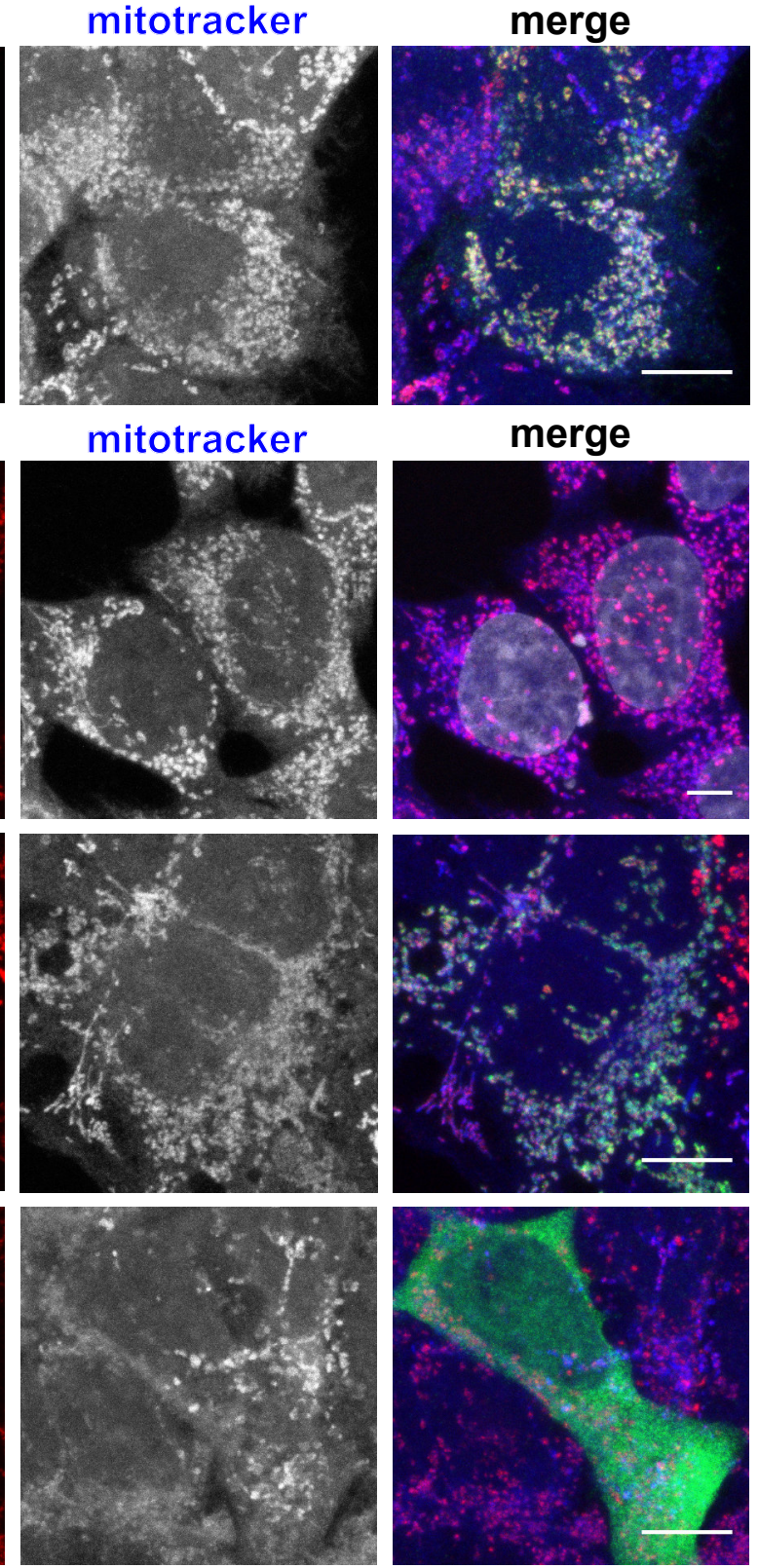

merge
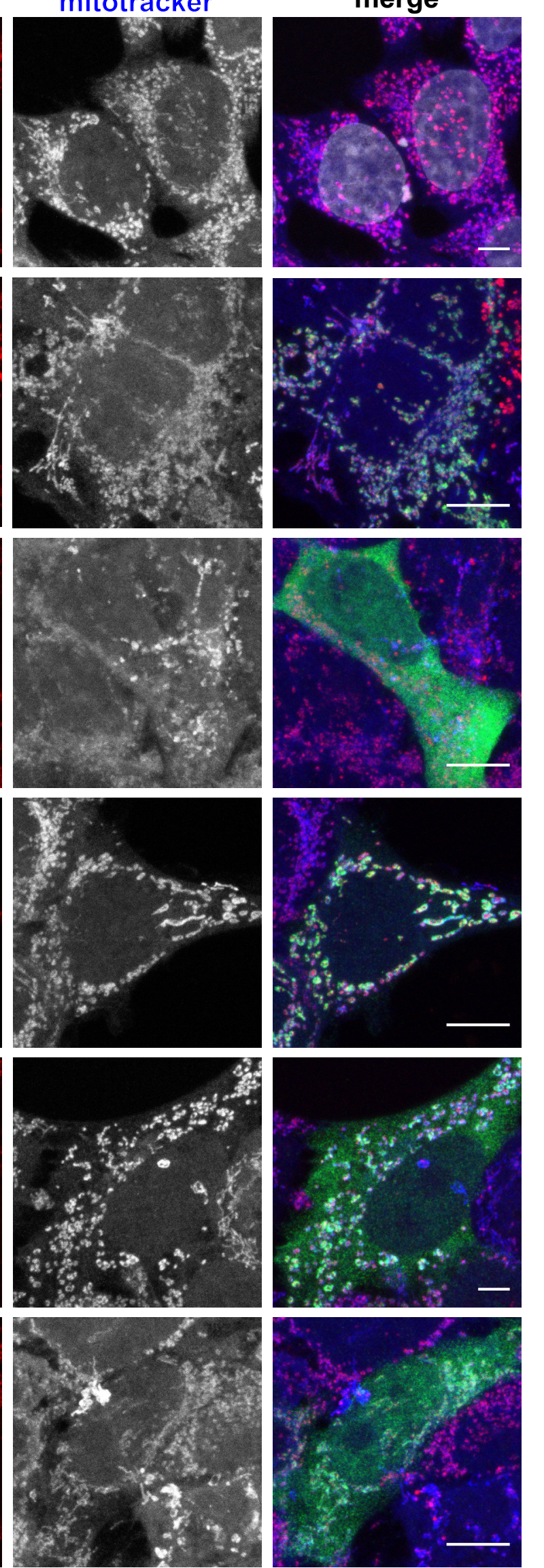
bioRxiv preprint doi: https://doi.org/10.1101/2021.01.31.428746; this version posted February 1, 2021. The copyright holder for this

preprint (which was not certified by peer review) is the_apthor/funder. All rights reserved. No reuse allowed without permission.

Figure S5

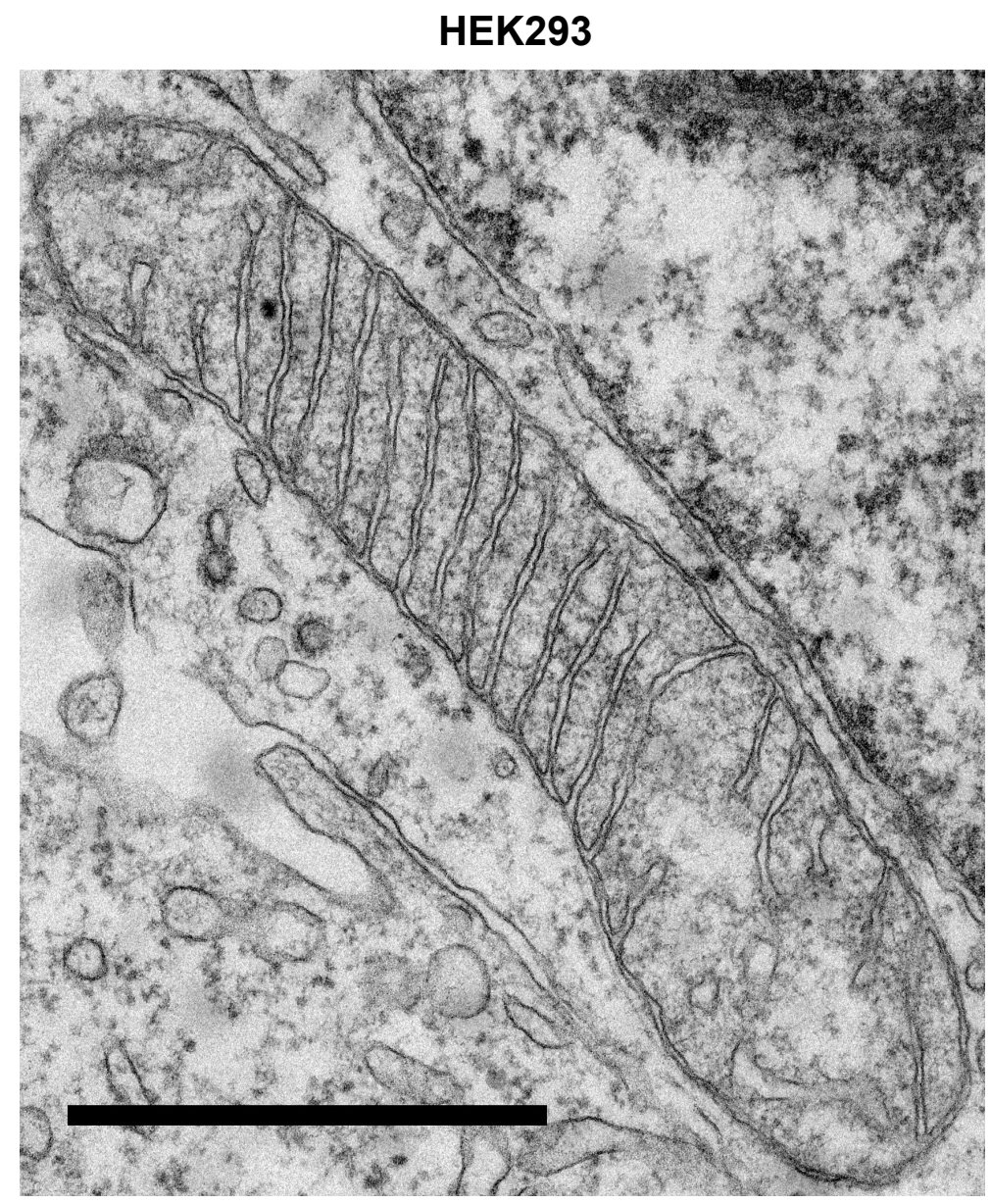

\section{HEK293+ myc-Rv1813c}

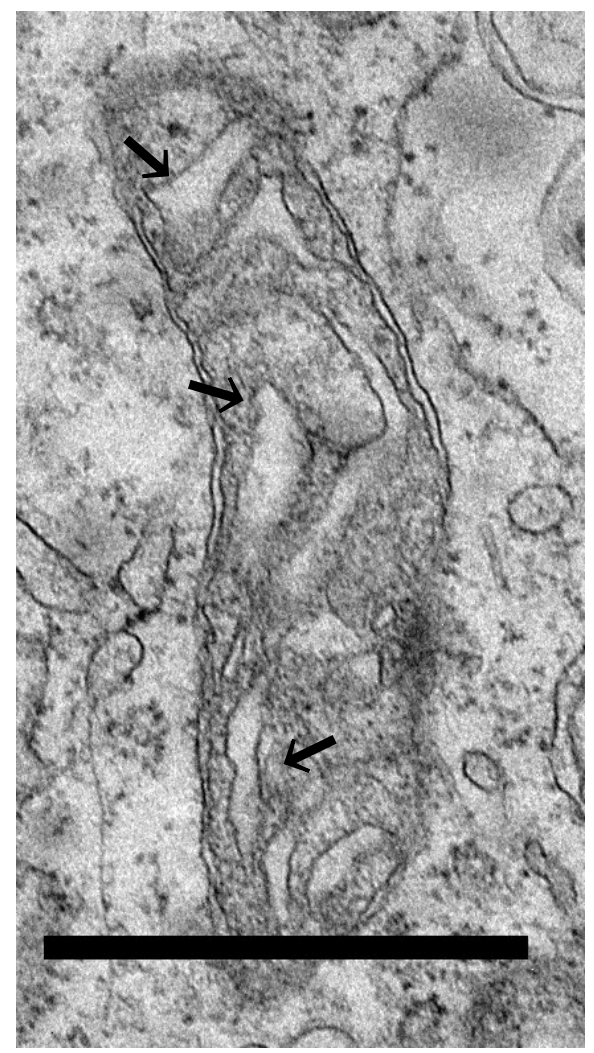

